\title{
Do olivine crystallization temperatures faithfully record mantle temperature variability?
}

\author{
Simon Matthews ${ }^{1 *}$, Kevin Wong ${ }^{1,2}$, Oliver Shorttle ${ }^{1,3}$, Marie Edmonds $^{1}$, John \\ Maclennan $^{1}$ \\ ${ }^{1}$ Department of Earth Sciences, University of Cambridge, Cambridge, U.K., CB2 3EQ \\ ${ }^{2}$ School of Earth and Environment, University of Leeds, Leeds, U.K., LS2 9JT \\ ${ }^{3}$ Institute of Astronomy, University of Cambridge, Cambridge, U.K., CB3 OHA
}

Manuscript accepted for publication in G3 on 1st February 2021.

\section{Key Points:}

- Hawaiian olivines crystallize at hotter temperatures than olivines in MORB

- Models are developed to link crystallization temperature to mantle temperature

- Mantle plumes may have had a similar distribution of temperatures throughout the Phanerozoic

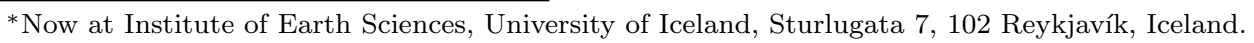

Corresponding author: Simon Matthews, simonm@hi.is 


\begin{abstract}
Crystallization temperatures of primitive olivine crystals have been widely used as both a proxy for, or an intermediate step in calculating, mantle temperatures. The olivine-spinel aluminum-exchange thermometer has been applied to samples from mid-ocean ridges and large igneous provinces, yielding considerable variability in olivine crystallization temperatures. We supplement the existing data with new crystallization temperature estimates for Hawaii, between $1282 \pm 21$ and $1375 \pm 19^{\circ} \mathrm{C}$.
\end{abstract}

Magmatic temperatures may be linked to mantle temperatures if the thermal changes during melting can be quantified. The magnitude of this temperature change depends on melt fraction, itself controlled by mantle temperature, mantle composition and lithosphere thickness. Both mantle composition and lithosphere thickness vary spatially and temporally, with systematic differences between mid-ocean ridges, ocean islands and large igneous provinces. For crystallization temperatures to provide robust evidence of mantle temperature variability, the controls of lithosphere thickness and mantle lithology on crystallization temperature must be isolated.

We develop a multi-lithology melting model for predicting crystallization temperatures of magmas in both intra-plate volcanic provinces and mid-ocean ridges. We find that the high crystallization temperatures seen at mantle plume localities do require high mantle temperatures. In the absence of further constraints on mantle lithology or melt productivity, we cannot robustly infer variable plume temperatures between ocean-islands and large igneous provinces from crystallization temperatures alone; for example, the extremely high crystallization temperatures obtained for the Tortugal Phanerozoic komatiite could derive from mantle of comparable temperature to modern-day Hawaii. This work demonstrates the limit of petrological thermometers when other geodynamic parameters are poorly known.

\title{
1 Introduction
}

Temperature variations in Earth's mantle drive its vigorous convective circulation, which governs the thermal and chemical exchanges between Earth's interior and exterior reservoirs. When convective upwellings, or plumes, first impact the Earth's lithospheric shell, voluminous magma generation creates large igneous provinces (LIPs) (e.g., Campbell \& Griffiths, 1990; White \& $\mathrm{M}^{\mathrm{c}}$ Kenzie, 1989). Many regions of modern-day intra-plate magmatism have also been linked to melting in plumes, with the plume's magma productivity diminishing over time (e.g., Wilson, 1973; Richards et al., 1989).

Mapping the spatial and temporal variability in mantle plume temperatures is key for constraining dynamical models of mantle convection (e.g., Campbell et al., 1989; Griffiths \& Campbell, 1990; Farnetani \& Richards, 1995; Dannberg \& Sobolev, 2015) and for understanding the evolution of magmatism throughout Earth history (e.g., Herzberg \& Gazel, 2009; Putirka, 2016). A variety of geochemical and geophysical observations have been interpreted as indicating that modern-day mantle plume temperatures vary substantially (e.g., Putirka, 2008a; Herzberg \& Asimow, 2015) and that individual plume temperatures may have changed through time (e.g., White, 1993; Parnell-Turner et al., 2014), particularly in the transition from large igneous province to ocean island volcanism (e.g., Thompson \& Gibson, 2000; Hole \& Millett, 2016; Spice et al., 2016).

A significant challenge in estimating mantle temperature variability is raised by variations in the tectonic regime of volcanism; mantle dynamics, the melting process, and mantle composition are likely to vary systematically with tectonic regime. Accounting adequately for these parameters when calculating mantle temperatures is particularly important when comparing the mantle sampled by mid-ocean ridge basalt (MORB), ocean-island basalt (OIB), and LIP magmatism. It also presents a challenge when extending methods of mantle temperature estimation into deep time, where these geodynamic parameters are more poorly constrained. 


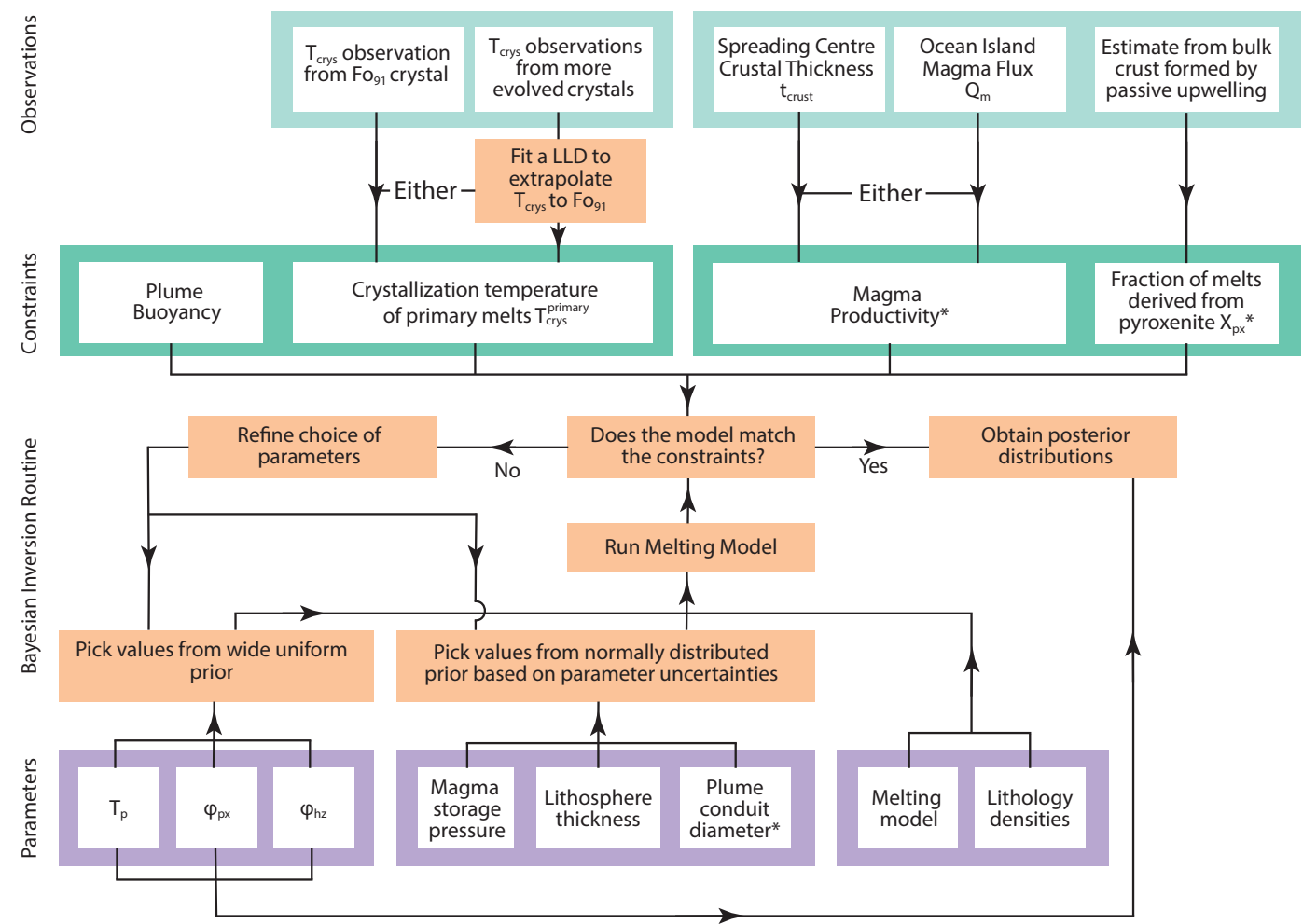

Figure 1. Summary of our approach to estimating mantle potential temperature, $T_{p}$, pyroxenite fraction, $\phi_{\mathrm{px}}$, harzburgite fraction, $\phi_{\mathrm{hz}}$, from raw observations of $T_{\mathrm{crys}}$ and magmatic flux. *Parameters not used in every inversion.

In this study we consider how well variations in crystallization temperature of primitive olivine crystals can constrain the spatial and temporal variability in mantle plume temperatures. To this end we use crystallization temperatures obtained from the olivinespinel aluminum-exchange thermometer (Coogan et al., 2014, Section 2). As a reference for modern-day OIB magmatism, we present new olivine crystallization temperatures for Hawaii (Section 3). In Section 4 we develop a toolkit for extracting the temperature at which magmas most likely began to crystallize, when olivine populations have highly variable crystallization temperature. By extending the mantle melting models developed by Matthews et al. (2016) and Shorttle et al. (2014) we quantify the relationship between crystallization temperature and mantle temperature, subject to variable tectonic setting and mantle composition (Section 5). Finally we invert our melting model (Section 6) to quantify mantle temperatures, using both our new crystallization temperature dataset, and similar datasets for global MORB, OIB and LIP localities (Section 7). Our approach is summarised in Figure 1.

\subsection{The ubiquity of harzburgite in the mantle}

Harzburgitic residues are the inevitable products of extensive melt extraction from the mantle. It might be expected that mantle harzburgites have been generated throughout Earth's history, initially making up lithospheric mantle, but ultimately being convectively stirred back into the mantle (e.g., Langmuir et al., 1992). Harzburgite units are observed at the base of ophiolites, thought to represent the residue of melting beneath the ridge crest (e.g., Boudier \& Coleman, 1981; Godard et al., 2000), confirming that harzburgitic rocks are produced, at least at some spreading centres. Their very origin as melting residues means 
that they are both extremely refractory and highly depleted in trace elements. In some melting regions harzburgitic mantle components may not melt at all, and even if they do, the trace element budget of erupted basalts will be overwhelmed by less depleted mantle components, and any isotopic record of extreme depletion will be rapidly mixed out (Rudge et al., 2013; Byerly \& Lassiter, 2014). Nevertheless, isotope ratio evidence for the presence of ancient and extremely depleted mantle components has been found in both MORB lavas (Salters et al., 2011) and OIB melt inclusions (Stracke et al., 2019)

Whilst we might expect radiogenic isotope signatures of extreme melt depletion to go hand-in-hand with lithological evolution to harzburgite, isotope ratios do not directly constrain source lithology. More direct evidence for the ubiquity of harzburgite in the convecting mantle comes from mantle peridotites now exposed at Earth's surface. Harzburgitic abyssal peridotites are seen in a number of spreading segments which have only small amounts of melt generation (Seyler et al., 2004; Paulick et al., 2006; Lassiter et al., 2014; D'Errico et al., 2016). The absence of substantial melt generation suggests that these harzburgites were generated in an ancient melting event and have been recycled through the convecting mantle. This is supported by extremely depleted radiogenic isotope ratios in these abyssal peridotites (Harvey et al., 2006; Liu et al., 2008; Warren et al., 2009; Stracke et al., 2011; Warren \& Shirey, 2012; Mallick et al., 2015), in addition to some ocean-island harzburgite xenoliths (Salters \& Zindler, 1995; Bizimis et al., 2007), which together were described as unequivocal evidence for ancient melt-extraction by Warren (2016).

Further indirect constraints on harzburgite abundances come from modelling by Shorttle et al. (2014) and Matthews et al. (2016), who incorporated a non-melting harzburgite component into their melting models. Shorttle et al. (2014) calculated plume buoyancy as a function of mantle temperature, pyroxenite fraction, and harzburgite fraction, and demonstrated that a significant quantity of harzburgite is required in the Iceland and Hawaiian plumes to satisfy plume volume flux constraints. Matthews et al. (2016) further constrained a harzburgite fraction of $47_{-19}^{+16} \%$ in the Icelandic plume in order to simultaneously recreate the trace element concentrations, crustal thickness, and crystallization temperatures in Iceland's Northern Volcanic Zone. The same process suggested a similar harzburgite fraction in the mantle beneath the Siqueiros fracture zone on the East Pacific Rise.

It is, therefore, very unlikely that there is not at least some harzburgite present in the mantle whence MORB and OIB derive. Whilst the harzburgite component might not contribute much, or any, magma, it will have an effect on the geothermal gradient in the melting region in its capacity as a thermal buffer (Phipps Morgan, 2001; Shorttle et al., 2014; Matthews et al., 2016). This influence on the thermal structure of the melting region will affect the temperatures at which magmas leave the mantle and ultimately begin crystallising (Matthews et al., 2016) and could change both their major- and trace-element compositions (Appendix A). For these reasons, the models we present here allow, but do not require, significant mantle harzburgite fractions. The uncertainty in harzburgite prevalence has a large contribution to the propagated uncertainty on our estimates of $T_{p}$, and is one among many reasons why diverse primary crystallization temperatures could be consistent with similar mantle $T_{p}$.

We emphasise that when we discuss mantle harzburgite we are considering harzburgitic lithologies present before the onset of the melting event we are tracing. Additionally, in some locations, melting of the lherzolite and pyroxenite lithologies is predicted to continue until clinopyroxene-exhaustion, which will leave behind a harzburgitic residue. This behaviour is explicitly included within the lherzolite and pyroxenite melting models.

\subsubsection{The effects of harzburgite and pyroxenite on mantle melt fractions}

When a considerable quantity of refractory (harzburgite) or anomalously fusible (pyroxenite) material is present in the mantle it affects both the bulk melt fraction and the melt fractions of the other lithologies present (Shorttle et al., 2014; Matthews et al., 2016). 
Substantially lower quantities, or even zero, melt may be generated from a harzburgitic component during upwelling. This decreases the bulk melt fraction, and consequently the crustal thickness at spreading ridges, or magmatic flux more generally. However, since there is no latent heat being extracted by harzburgite melting, more heat energy is available to the other lithologies, assuming they remain in thermal equilibrium with each other. Any lherzolite or pyroxenite present may, therefore, achieve higher melt fractions than they would in a harzburgite-free mantle of the same temperature.

Conversely, when a substantial quantity of anomalously fusible material is present, the large extent of melting will extract more latent heat, decreasing the heat energy available to the other lithologies. The presence of pyroxenite may thus have the opposite effect of harzburgite on the other lithologies: lower melt fractions will be obtained than at the same temperature, though the bulk melt fraction may be higher owing to the large contribution from fusible pyroxenite.

The composition of lherzolite- and pyroxenite-derived melts is determined by the pressure and temperature (or melt-fraction) at which they were formed. In Section 1.2.1 we briefly review approaches utilising magma composition to estimate mantle temperatures, the first step of which is to estimate the mantle melt fraction. Necessarily, a melt fraction estimated in this manner applies only to a single lithology, generally lherzolite. If there is a significant harzburgite fraction or pyroxenite fraction, the bulk melt fraction of the mantle may be significantly lower or higher than the lherzolite melt fraction. It is important, therefore, to distinguish bulk mantle melt fraction from the melt fractions of individual lithologies.

\subsection{Estimating mantle temperatures}

An assortment of petrological and geophysical techniques have been employed in estimating mantle temperature variability. Whilst geophysical observations can provide constraints on modern-day mantle temperatures (e.g., Watson \& McKenzie, 1991; Jenkins et al., 2016), our focus is on using petrological observations. Petrological observations can be made not only on recently erupted basalts, representing the present-day thermal state of plumes, but also on ancient volcanics associated with LIPs. Petrological techniques take advantage of the controls exerted by temperature and pressure on mineral stability and magma composition, to constrain temperatures within magmatic systems. A model for the thermal changes accompanying mantle decompression and melting must then be applied to estimate the temperature of solid mantle beneath the melting region. To normalise out the effect of decompression on mantle temperature, we use the mantle potential temperature, $T_{p}$ : the temperature mantle material would have were it to be transported to the surface without chemical change (Cawthorn, 1975; Mc Kenzie \& Bickle, 1988).

\subsubsection{Estimating $T_{p}$ from magma chemistry}

The composition of primary mantle melts betrays the temperatures and pressures at which they formed, and the mantle lithology whence they derived. Experimental work (e.g., Kinzler \& Grove, 1992) has constrained the relationship between melting conditions and primary melt chemistry, enabling the development of empirical expressions to quantify that relationship (e.g., Mc Kenzie \& Bickle, 1988; Lee et al., 2009). However, erupted lavas are not primary mantle melts, having undergone fractional crystallization and mixing, progressively modifying their chemistry (e.g., O’Hara, 1965; O'Hara, 1968; Klein \& Langmuir, 1987; Grove et al., 1992; Maclennan, 2008; Rudge et al., 2013; Hole \& Natland, 2019). The presence of pyroxenite in the mantle source of melts creates additional complexity; at any given pressure and temperature, the chemistry of melts in equilibrium with pyroxenite is different from melts in equilibrium with mantle lherzolite (e.g., Hirschmann \& Stolper, 1996; Lambart et al., 2013; Jennings et al., 2016). The chemistry of a mixed magma, containing substantial contributions from both lherzolite and pyroxenite, is difficult to use to directly 
estimate melting temperature and pressure. Fortunately, volcanic provinces often have lavas with minimal contribution from pyroxenite melts, even where pyroxenite is present in the mantle source (e.g., Herzberg \& Asimow, 2008; Shorttle \& Maclennan, 2011).

For the chemistry of natural lavas to be of use in obtaining the temperature and pressure of magma genesis, the composition of their ancestral primary mantle melt must be estimated by undoing the chemical changes caused by fractional crystallization. The PRIMELT3 program (Herzberg \& Asimow, 2015) implements an algorithm that adds olivine back into an olivine-saturated lava until its composition resembles a primary melt of the KR4003 lherzolite (Walter, 1998). When lithologically homogeneous mantle melts by adiabatic decompression, the melt $\mathrm{MgO}$ content remains approximately constant throughout melting (Herzberg \& O'Hara, 2002), providing a simple relationship between primary melt $\mathrm{MgO}$ and mantle $T_{p}$, which is utilized by PRIMELT3. Furthermore, the reconstructed magma composition constrains the melt fraction, which may be combined with the $T_{p}$ estimate to obtain the minimum pressure of melting. However, the presence of substantial fractions of refractory harzburgite or fusible pyroxenite will change the temperature gradient in the melting region, complicating the simple relationship between primary magma $\mathrm{MgO}$ and mantle $T_{p}$ (Appendix A).

Trace element concentrations in lavas have also been inverted to estimate mantle $T_{p}$ ( $\mathrm{M}^{\mathrm{c}}$ Kenzie \& O'Nions, 1991). The concentrations of rare earth elements (REEs) in mantle melts, relative to the concentration in their source, are straightforward to predict, given the melt fraction and pressure. If mantle REE concentrations are known, melt fraction vs depth curves can be constructed by iterative fitting of lava REE chemistry. The melt fraction curves are then compared to the expected evolution of melt fraction with depth for different values of mantle $T_{p}$. However, plume-driven (active) upwelling (Maclennan et al., 2001), lithological heterogeneity (Appendix A), and trace element heterogeneity (Brown et al., 2020a) can complicate the application of REE-inversions.

\subsubsection{Estimating $T_{p}$ from crystallization temperatures}

Rather than estimating $T_{p}$ directly from lava chemistry, Putirka et al. (2007) developed a method where primary olivine crystallization temperatures are estimated first, followed by a correction for the latent heat of melting. Both steps utilize lava chemistry. The primary mantle melt $X_{\mathrm{Mg}}$ and $X_{\mathrm{Fe}}$ are reconstructed by back-projecting the olivine-controlled liquid line of descent, inferred from the lava chemistry, to find a magma that is in $\mathrm{Mg}$-Fe equilibrium with the most forsteritic olivine thought to crystallize from the melt. The olivine-liquid MgFe exchange thermometer (Putirka, 2005; Putirka et al., 2007) is then used to obtain a crystallization temperature. The other major-element oxide concentrations in the primary melt are then reconstructed by adding olivine to a lava composition until the $X_{\mathrm{Mg}}$ and $X_{\mathrm{Fe}}$ inferred in the previous step are obtained, analogous to the PRIMELT3 alogorithm. Using the reconstructed melt composition the melt fraction is estimated, from which the latent heat of melting and the associated temperature drop are calculated. Combining the calculated temperature-drop due to melting, with the crystallization temperature, yields an estimate of the mantle $T_{p}$.

This method is simple to apply, but a major uncertainty arises from making the assumption that a particular lava sample (or its ancestral melts) was ever in equilibrium with the chosen olivine composition. Indeed, the lava samples used as the starting point for the calculation represent mixed melts. It is likely that only the most extreme unmixed melts were in equilibrium with the most forsteritic olivines, potentially leading to overestimation of primary crystallization temperatures (Herzberg, 2011; Matthews et al., 2016). Furthermore, with particular relevance to Hawaii, Wieser et al. (2019) demonstrated that the most forsteritic olivine crystals from Kìlauea are not cogenetic with their carrier melts, even prior to mixing. 


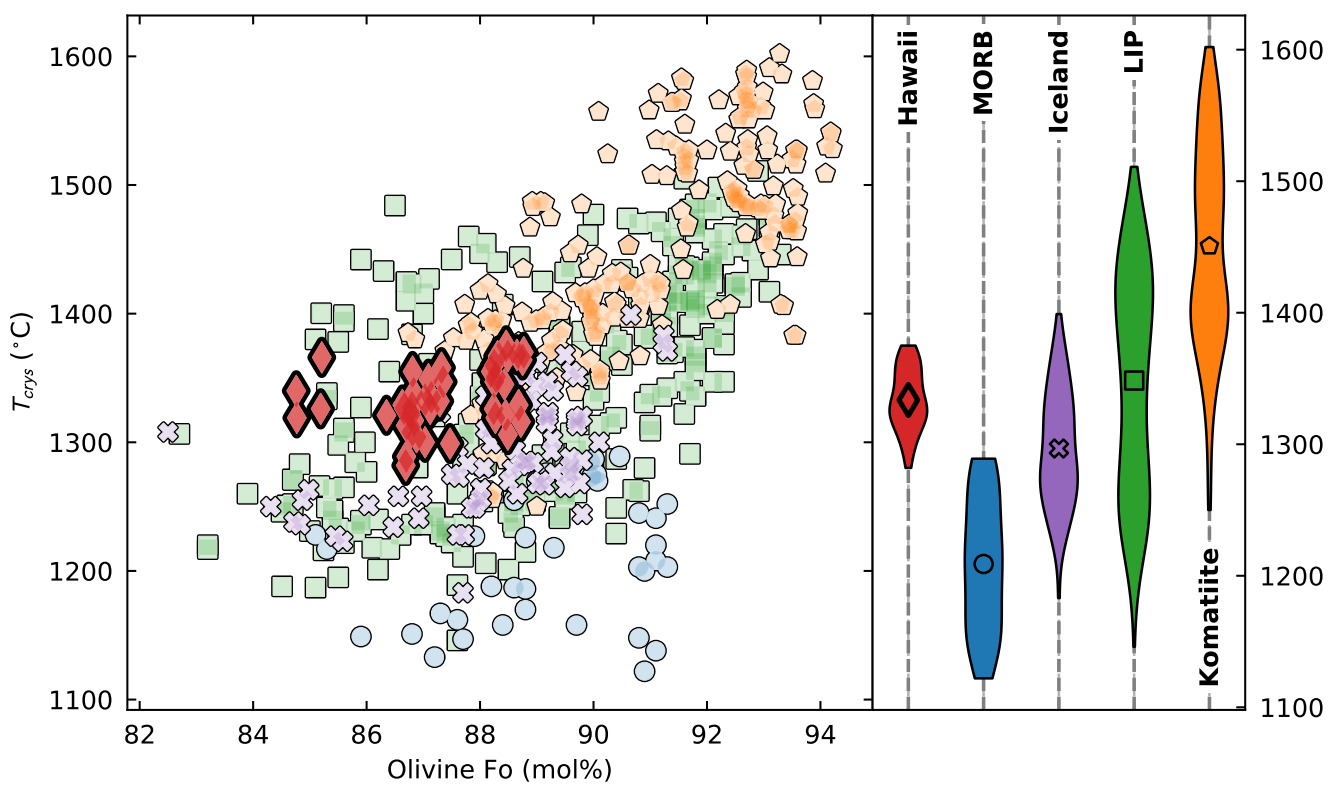

Figure 2. New Hawaiian olivine crystallization temperature estimates, shown alongside a global compilation of olivine-spinel aluminum-exchange crystallization temperatures. The left-hand side of the figure shows the individual olivine crystallization temperatures plotted versus olivine core composition (where Fo $>82$ ), and the right-hand side shows crystallization temperature kernel density estimates. The compilation is subdivided into mid-ocean ridge basalt (MORB) (this study and Coogan et al., 2014), Iceland (Matthews et al., 2016; Spice et al., 2016), large igneous provinces (LIP) (Coogan et al., 2014; Heinonen et al., 2015; Jennings et al., 2019; Spice et al., 2016; Trela et al., 2017; R. Xu \& Liu, 2016), and komatiites (A. V. Sobolev et al., 2016; Trela et al., 2015; Waterton et al., 2017).

The olivine-spinel aluminum-exchange thermometer (Wan et al., 2008; Coogan et al., 2014) can be used to estimate primitive olivine crystallization temperatures and, in contrast to the approaches described above, reconstruction of a primary magma composition is not required. Instead, co-existing olivine and spinel crystals that were in equilibrium at the time of crystallization must be identified. For olivine-spinel equilibrium to record primary crystallization temperatures, the phases must have saturated at a similar time, and these early formed crystals must have been erupted. The common occurrence of spinel inclusions in primitive olivine hosts indicates that spinel and olivine co-saturate early in many locations (e.g., Coogan et al., 2014; Spice et al., 2016; Matthews et al., 2016; Trela et al., 2017), and the close spatial relationship suggests the phases were in equilibrium with the same melt (and, therefore, each other). However, in other locations (including Hawaii), spinel inclusions are only seen in more evolved olivines, and experimental work (Eggins, 1992; Wagner \& Grove, 1998; Maaløe, 2004) indicates olivine and spinel co-saturation occurs at temperatures far below the liquidus. In Section 4 we consider how best to compare crystallization temperatures between locations where olivine and spinel co-saturate at different times. Whilst $\mathrm{Al}$ hosted in olivine octahedral sites via a vacancy-coupled substitution may diffuse extremely rapidly (Zhukova et al., 2017), the majority of the Al incorporated into olivine is likely to be extremely slow diffusing (Spandler \& O'Neill, 2010), making it unlikely that the thermometer will be reset following crystallization (Coogan et al., 2014). Application of the thermometer has yielded systematic differences in crystallization temperature between MORB, Iceland, LIPs and komatiites (Figure 2). 
Since we can assess the reliability of the olivine-spinel aluminum-exchange temperatures using the petrological context of the crystals, and the temperature estimates are independent of assumptions about melt chemistry or mantle composition, we use this technique in preference to the others summarized above. However, some of the datasets in the global compilation do not contain the most primitive olivines likely to have formed. Comparisons to such datasets must, therefore, be done with careful consideration of the missing crystallization history (Section 4). Once the crystallization temperatures of the most primitive olivines have been estimated, either directly from the thermometer or by extrapolating the missing crystallization history, the temperature reduction due to melting must be estimated (the latent heat of melting correction). Only then can the mantle $T_{p}$ be calculated.

The magnitude of the latent heat of melting correction is directly related to the total melt fraction. The approaches developed by $\mathrm{M}^{\mathrm{C}}$ Kenzie and O'Nions (1991), Putirka et al. (2007), and Herzberg and Gazel (2009), reviewed above, all estimate the total melt fraction from lava composition. However, the melt fraction estimated with these approaches pertains only to the lherzolite mantle component, which may bear little resemblance to the total melt fraction when there are significant mantle pyroxenite and harzburgite fractions (Appendix A). The total melt fraction can also be constrained using observations of magmatic productivity ( $\mathrm{M}^{\mathrm{C}}$ Kenzie \& Bickle, 1988; Shorttle et al., 2014) and by estimating the geothermal gradient through the melting region (Matthews et al., 2016; Jennings et al., 2019).

At all but the slowest spreading mid-ocean ridges the crustal thickness is a direct constraint on the melt fraction, and is independent of spreading rate and ridge geometry (e.g., Reid \& Jackson, 1981; Bown \& White, 1994). Where decompression melting results from plume-driven (active) mantle upwelling, such as at many ocean islands, the total melt fraction may be estimated from the magma flux, though the upwelling velocity and geometry of the plume must be assumed (e.g., Watson \& M Kenzie, 1991; Shorttle et al., 2014). Where available, we use either the crustal thickness at spreading centres, or the magma flux at ocean islands, to constrain our $T_{p}$ inversions.

In the absence of a tight constraint on the melt fraction, the range of plausible latent heat of melting corrections might be considered. This can be achieved by forward modelling the geotherm throughout the melting region to find the range of solutions able to match observed crystallization temperatures. Once melts leave the melting region they must traverse the lithosphere until they stall in a crustal magma chamber. During transit the melts are likely to thermally equilibrate with the surrounding lithosphere, their temperatures tending towards the geotherm. However, calculating the geothermal gradient in the lithosphere is more complex, being controlled both by the advection by magmas and the conduction of heat through the Earth's surface. We make the assumption that advection of heat by magma movement dominates over conductive heat loss. In this scenario the geotherm will not deviate far from the liquid adiabat, any difference being small compared to the other uncertainties.

Jennings et al. (2019) employed the forward modelling approach when converting their crystallization temperatures for the Etendeka LIP into a mantle $T_{p}$. They model melting assuming a homogeneous mantle composition of KLB-1 lherzolite, and that the melts follow a liquid adiabat whilst traversing the lithosphere. In estimating $T_{p}$ for MORB and Iceland, Matthews et al. (2016) also forward modelled geotherms, but allowed for variable proportions of harzburgite and pyroxenite in the mantle, constraining their $T_{p}$ solutions further with observations of melt production rates (constrained by crustal thicknesses). We take this approach here, using a forward model of multi-lithologic melting to estimate the geotherm (Section 5), constrained with rates of melt production where estimates can be made (Section $6)$.

Whilst geophysical techniques are used to estimate present-day lithospheric thickness (e.g., Priestley \& $\mathrm{M}^{\mathrm{c}}$ Kenzie, 2006; Geissler et al., 2010), we must rely on the rock record for 
ancient magmatic provinces. The major and trace element chemistry of lavas not only constrains mantle $T_{p}$, but is also sensitive to the minimum pressure of melting. Both PRIMELT3 (Herzberg \& Asimow, 2015) and REE inversions ( ${ }^{\mathrm{c}}$ Kenzie \& O'Nions, 1991) have been used to predict the minimum melting pressure. Whilst the estimates of lithospheric thickness derived from these techniques have the same limitations as their $T_{p}$ estimates, they provide one of the few constraints on the lithospheric thickness contemporaneous with past melting events.

\section{Materials and analytical methods}

Olivine crystals were extracted from crushed tephra collected from the first episode of the Kîlauea Iki 1959 eruption, Hawaii (Sides et al., 2014a), and from the Siqueiros fracture zone whole rock sample 2384-1 (Perfit et al., 1996). Only crystals containing spinel inclusions fully enclosed by olivine were selected, avoiding spinels that are likely to have re-equilibrated with the surrounding magma following entrapment. The crystals were mounted in epoxy resin, then ground and polished with silicon carbide papers and diamond suspensions. The Loihi olivine crystals were previously prepared and analysed for melt inclusion chemistry by Sides et al. (2014a).

The Coogan et al. (2014) olivine-spinel aluminum-exchange thermometer requires the $\mathrm{Al}_{2} \mathrm{O}_{3}$ content of co-existing olivine and spinel, and the $\mathrm{Cr} \#$ of the spinel:

$$
T_{\text {crys }}(K)=\frac{10,000}{0.575+0.884 C r \#-0.897 \ln \left(k_{d}\right)}
$$

where,

$$
k_{d}=\frac{\mathrm{Al}_{2} \mathrm{O}_{3}^{\text {olivine }}}{\mathrm{Al}_{2} \mathrm{O}_{3}^{\text {spinel }}}
$$

and,

$$
C r \#=\frac{\mathrm{Cr}}{\mathrm{Cr}+\mathrm{Al}} .
$$

In these equations $\mathrm{Al}_{2} \mathrm{O}_{3}$ concentrations are in wt\%, and $\mathrm{Al}$ and $\mathrm{Cr}$ are molar quantities. All chemical data were obtained using electron probe micro-analysis (Section 2.1). Error propagation was performed using a Monte Carlo method as described by Matthews et al. (2016) using a standard deviation of $14^{\circ} \mathrm{C}$ as the combined uncertainty on the thermometer calibration. This estimate of the uncertainty represents a minimum bound on the uncertainty as it is derived from the same data used to calibrate the thermometer by Coogan et al. (2014).

\subsection{Electron probe micro-analysis}

Analyses were performed using the Cameca SX-100 Electron Microprobe at the Department of Earth Sciences, University of Cambridge, over two sessions. The first session was dedicated to obtaining qualitative maps of the $\mathrm{Al}_{2} \mathrm{O}_{3}$ distribution in olivine crystals containing spinel inclusions (Section 2.1.1). These maps were used to guide the selection of points for quantitative analysis in the second session (Section 2.1.2), enabling us to characterize and avoid $\mathrm{Al}_{2} \mathrm{O}_{3}$ zoning, as observed in some crystals by Coogan et al. (2014) and Matthews et al. (2016).

\subsubsection{Qualitative element mapping}

Preliminary qualitative mapping of olivine $\mathrm{Al}$ and $\mathrm{P}$ concentrations adjacent to spinel inclusions was performed using a $15 \mathrm{kV} 200 \mathrm{nA}$ beam with a dwell time of $0.5 \mathrm{~s}$ per $\sim 7 \mu \mathrm{m}$ pixel. All maps were acquired by moving the stage beneath a static beam, and counts were recorded for the $\mathrm{Al} \mathrm{K} \alpha$ peak using the LTAP crystal, and for the $\mathrm{P}$ K $\alpha$ peak using the LPET crystal. Applying the same technique to a crystal where Al-zoning was previously observed 


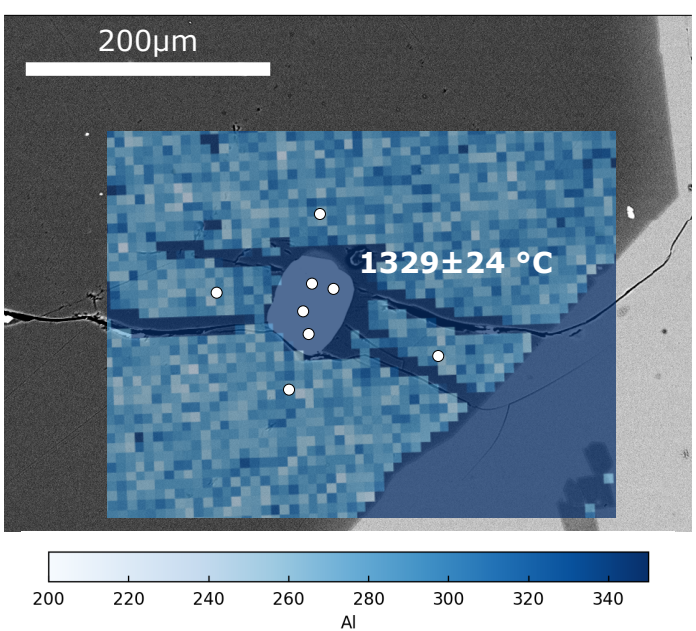

Figure 3. Back-scatter electron image superimposed with the qualitative Al map for olivinespinel pair L_F4. The color scale shows the counts on the Al K $\alpha$ peak. White dots show the location of quantitative analyses. The temperature calculated for this olivine-spinel pair is shown.

by Matthews et al. (2016) demonstrated these conditions were appropriate for identifying zoning (Supporting Figure S.1.). The maps are provided in Supporting Data Set S.4.

Using the maps of $\mathrm{Al}$ and $\mathrm{P}$ concentrations, we selected points for quantitative analysis, preferring regions of homogeneous $\mathrm{Al}$ concentration and low $\mathrm{P}$ concentration adjacent to the spinel inclusion (Figure 3). Regions of high $\mathrm{P}$ concentration are best avoided since its incorporation into olivine correlates with increased uptake of Al (Coogan et al., 2014). The majority of crystals did not show any variability in $\mathrm{Al}$ concentration on the scale of the map, and $\mathrm{P}$ concentrations were below the detection limit.

\subsubsection{Quantitative element analysis}

Quantitative analyses were performed in a single session using a $15 \mathrm{kV}$ beam focused to $1 \mu \mathrm{m}$ at $100 \mathrm{nA}$ for olivine and $40 \mathrm{nA}$ for spinel. Calibration was performed using natural and synthetic standards (Supporting Table S.1.). Instrument drift, precision and accuracy were monitored by regular analysis of natural secondary standard materials (Supporting Data Set S.1.). Counting times and crystals used are detailed in Supporting Table S.2.

The analytical setup achieved $\mathrm{Al}$ detection limits better than $23 \mathrm{ppm}$, significantly lower than the measured $\mathrm{Al}$ concentrations. Repeat analyses of the $\mathrm{Al}_{2} \mathrm{O}_{3}$ concentration in San Carlos olivine showed a 1 s.d. precision of $20 \mathrm{ppm}$, lower than the combined precision and accuracy of 25-30 ppmw estimated from counting statistics, which was propagated to the error in $T_{\text {crys }}$. Spinel $\mathrm{Fe}^{3+} / \mathrm{Fe}_{\mathrm{T}}$ was calculated from the electron probe data following the method of Droop (1987).

\section{Thermometry Results}

The composition of the olivine-spinel pairs is summarized in Figure 4, and the dataset is provided in Supporting Data Set S.2. The composition of the Hawaiian and Siquieros olivine crystals (Figure 4d) overlap with the compositions of crystals used to calibrate the thermometer by Coogan et al. (2014). The Siqueiros spinels have compositions very similar to the experimental crystals. The Hawaii spinels are offset to lower $\mathrm{Mg} \#$, lower $\mathrm{Al}_{2} \mathrm{O}_{3}$ concentration, and higher $\mathrm{Fe}_{2} \mathrm{O}_{3} / \mathrm{FeO}_{\mathrm{T}}$ than the experimental crystals, but have similar 

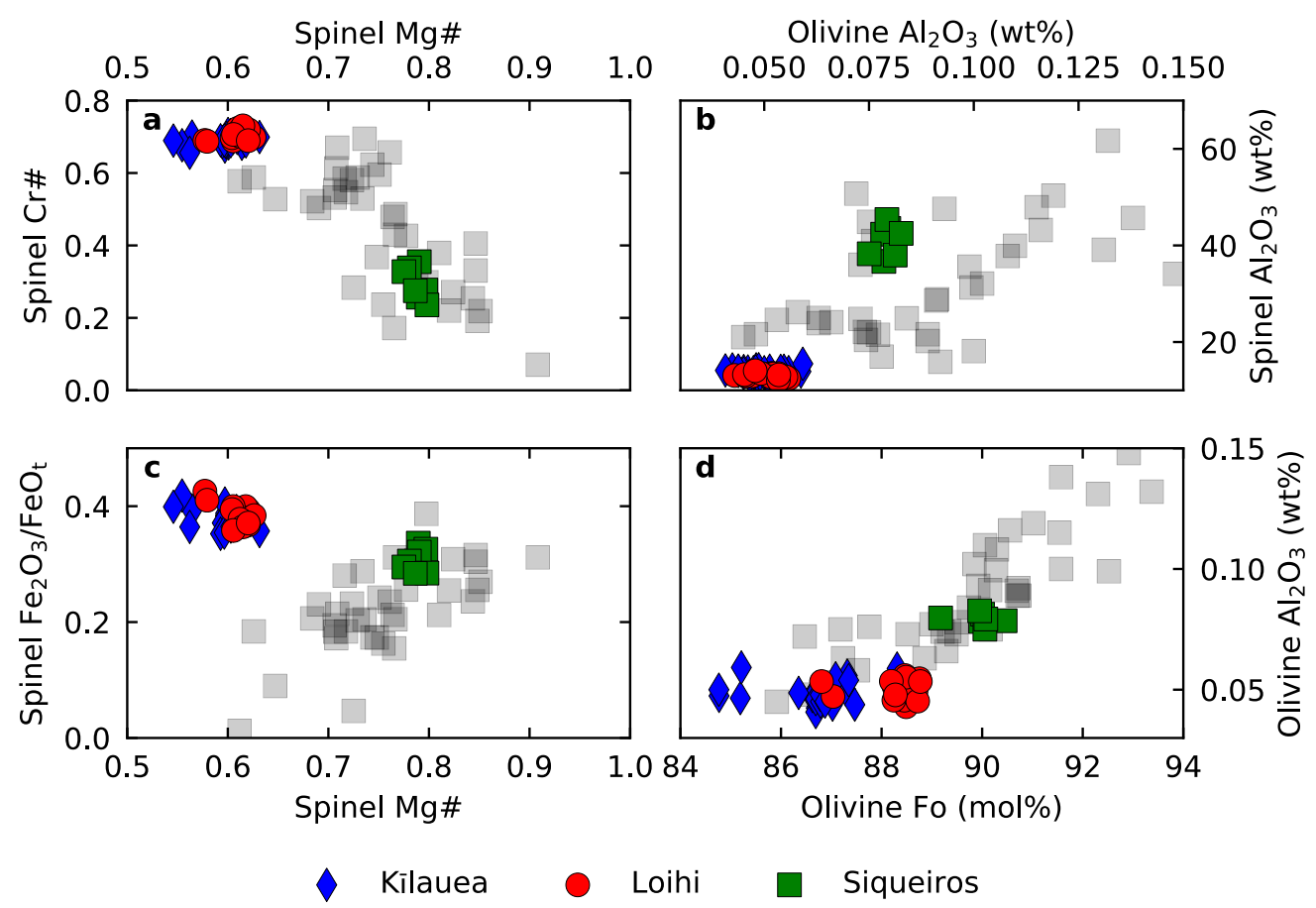

Figure 4. Summary of the compositions of the olivine and spinel crystals from Hawaii (Kìlauea and Loihi) and Siqueiros analysed in this study. The grey squares show the composition of olivine and spinel crystals used to calibrate the thermometer by Coogan et al. (2014). Uncertainties are smaller than the size of the symbols.

Cr\# to the highest Cr\# experimental spinels. These offsets between natural and experimental spinels are small, suggesting the thermometer calibration may still be applied with confidence.

Olivine-spinel pairs from Hawaii record temperatures from $1282 \pm 21^{\circ} \mathrm{C}$ to $1375 \pm 19^{\circ} \mathrm{C}$ (Figure 2). The mean crystallization temperature for Loihi, $1345^{\circ} \mathrm{C}$, is higher than that for Kìlauea, $1326^{\circ} \mathrm{C}$ (the standard errors in the means are $4^{\circ} \mathrm{C}$ and $5^{\circ} \mathrm{C}$, respectively). This small difference in mean crystallization temperature arises from the slightly lower $\mathrm{Al}_{2} \mathrm{O}_{3}$ concentration in Loihi spinels (Figure 4b). Where multiple spinel inclusions were analysed within the same host crystal, most recorded identical $T_{\text {crys }}$ within error; the few that did not were most likely entrapped at different stages of magma evolution.

The lower mean crystallization temperature of Kīlauea olivines coincides with a lower mean olivine Fo, consistent with being derived from more evolved magmas. However, within each subpopulation there is substantial crystallization temperature variability and no correlation with olivine composition; the implications of which, for inferring mantle $T_{p}$, are discussed in Section 4.

The Siqueiros olivine-spinel pairs record crystallization temperatures from $1270 \pm 16^{\circ} \mathrm{C}$ to $1289 \pm 17^{\circ} \mathrm{C}$, higher than, but within uncertainty of, the highest values obtained by Coogan et al. (2014). This small difference in Siqueiros olivine crystallization temperatures may reflect a small inter-lab bias in the EPMA analyses, or the crystals used in the two studies may represent different crystal populations. 


\section{Identifying crystallization temperatures of primitive basalts}

The temperature at which a magma first starts to crystallize olivine, $T_{\text {crys }}^{\text {primary }}$, is likely very close to the temperature at which it arrived in the magma chamber (Matthews et al., 2016). Olivine crystals then continue to form at progressively lower temperatures as the magma cools. When comparing datasets it is important to ensure variations in magmatic evolution are not aliased with the mantle signal. Fortunately, olivine composition closely tracks magmatic evolution, with the most primitive crystals being the most forsteritic. We assume, therefore, that olivines of composition $\mathrm{Fo}_{\geq 91}$ provide the most reliable record of $T_{\text {crys }}^{\text {primary }}$.

Many datasets exhibit substantial variability in $T_{\text {crys }}$ within their high forsterite populations (Figure 2 and Supplementary Figures S.2 and S.3). Variability in $T_{\text {crys }}$ that does not correlate with Fo might arise from crystallization of chemically heterogeneous magmas (Matthews et al., 2016, and Section 4.2) or diffusive re-equilibration of $\mathrm{Mg}$ and Fe with surrounding crystals and melt (Jennings et al., 2019, and Section 4.1), implying the highest $T_{\text {crys }}$ is most representative of $T_{\text {crys }}^{\text {primary }}$. Alternatively, the variability might be ascribed to analytical imprecision and variable attainment of Al-equilibrium between olivine and spinel. In this case, the mean $T_{\text {crys }}$ of the high forsterite population is the most appropriate estimate of $T_{\text {crys }}^{\text {primary }}$. We take the conservative approach of taking the mean of the high forsterite, high $T_{\text {crys }}$, population as our estimate of $T_{\text {crys }}^{\text {primary }}$ for such eruptions, as opposed to taking simply the highest $T_{\text {crys }}$ value.

Whether or not the most forsteritic olivines are present in erupted material depends on the unique dynamics of individual magmatic plumbing systems; consequently, many eruptions contain only a more evolved crystal cargo. Some of the datasets we invert for mantle $T_{p}$, including our new data from Hawaii, do not contain $\mathrm{Fo}_{>91}$ crystals with spinel inclusions. The role of magmatic evolution and coeval cooling must, therefore, be considered when obtaining $T_{\text {crys }}^{\text {primary }}$ from such datasets. One approach is to consider the $T_{\text {crys }}$ of evolved olivines as a robust minimum bound on the primary crystallization temperature $T_{\text {crys }}^{\text {primary }}$. However, for a meaningful comparison, the true $T_{\text {crys }}^{\text {primary }}$ should be estimated from the observed Fo- $T_{\text {crys }}$ systematics.

The combination of olivine composition and its crystallization temperature can be used to uniquely determine the mole fractions of $\mathrm{Mg}$ and Fe in its parental melt (Roeder \& Emslie, 1970). A liquid line of descent may then be calculated by the iterative application of a reverse-crystallization algorithm. First, a small amount of the olivine in equilibrium with this melt is added to the melt composition. Second, the temperature at which the new magma composition is olivine-saturated is found, and the new equilibrium olivine composition is identified. These steps are then repeated until the magma is in equilibrium with the most forsteritic olivine assumed to have crystallised from the melts. The methodology for these reverse-crystallization calculations, and the assumptions they require, are detailed in Supporting Text S1.

When employing this method, we must assume the magmas are sufficiently primitive that olivine and spinel are the only phases on the liquidus, and that the proportion of spinel crystallising is sufficiently small to have little effect on the magma composition. We must also make a decision about which olivine composition and $T_{\text {crys }}$ value provide the most appropriate starting point for the calculation. Which olivine should be chosen depends on whether diffusive resetting of Fo (Section 4.1) or crystallization from heterogeneous melts (Section 4.2) is responsible for the decoupling of Fo and $T_{\text {crys }}$. To assess the effect of our assumptions about estimating $T_{\text {crys }}^{\text {primary }}$, we use $T_{\text {crys }}^{\text {primary }}$ values calculated assuming both endmembers in our inversions for mantle $T_{p}$ (Section 6).

Another prerequisite for estimating $T_{\text {crys }}^{\text {primary }}$ with this method is knowing the value of equilibrium-olivine Fo at which the liquid line of descent extrapolation should be terminated. The most forsteritic olivine crystallized is likely to vary between locations (e.g., 

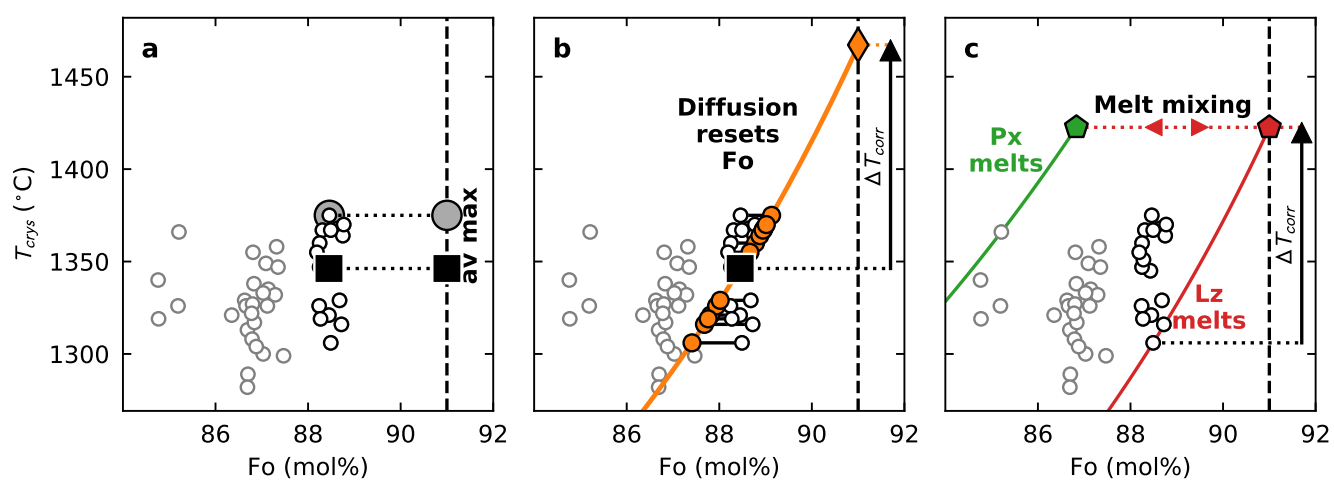

Figure 5. Three possible approaches to estimating the crystallization temperature of primitive melts from the distribution of the Hawaiian olivine-spinel crystallization temperatures. Only the most forsteritic sub-population is included in the calculations (shown by the circles with darker outlines). Panel a demonstrates an approach taking the average and maximum crystallization temperatures present. Panel b shows the result of extrapolating a liquid line of descent from the average crystallization temperature and olivine composition to Fo91 olivine, as would be in equilibrium with lherzolitic mantle. Panel c shows how two liquid lines of descent from melts of different composition bound the population of olivine crystals.

Figure 2; Putirka, 2005; Putirka et al., 2007, 2018). Whilst we could correct back to the most forsteritic crystal observed in each location, as done by Putirka (2005); Putirka et al. (2007, 2018), we cannot be certain that olivine crystals with higher forsterite contents were crystallised, but not erupted. For simplicity, we extend the liquid lines of descent back to Fo91 olivine in all correction calculations; any uncertainty introduced by this assumption being negligible compared to the uncertainty in which correction method should be applied.

\subsection{Diffusive resetting}

Diffusive re-equilibration of a crystal pile of variably forsteritic olivines will progressively shift the Fo of each crystal towards the population mean (Thomson \& Maclennan, 2012). The slow diffusion of Al through olivine means that the original olivine Al concentration is likely to be retained (Coogan et al., 2014). It follows that the discrepancy in diffusion rates can efficiently decouple $T_{\text {crys }}$ from Fo in a population of olivine crystals. If the initial diversity of Fo and $T_{\text {crys }}$ were derived from the fractional crystallization of a single magma, the population mean Fo and $T_{\text {crys }}$ will fall very close to the liquid line of descent (Figure $5 \mathrm{~b}$ ), making it an appropriate starting composition to use for calculating $\mathrm{T}_{\text {crys }}^{\text {primary }}$.

When a population of olivine crystals is derived from fractional crystallization of a single magma, followed by partial diffusive re-equilibration in a closed system, the highest values of $T_{\text {crys }}$ will be found only in crystals more forsteritic than the population mean, and the lowest values of $T_{\text {crys }}$ only in less forsteritic olivines. The Hawaii dataset does not exhibit this pattern (Figure 5). However, the diversity of melt inclusion trace element ratios demonstrate that the Kīlauea olivines are not derived from fractional crystallization of a single magma (Sides et al., 2014b; Wieser et al., 2019), we should therefore not expect crystals to conform to diffusive re-equilibration from a single liquid line of descent. Diffusion is still a plausible mechanism for generating the Fo- $T_{\text {crys }}$ decoupling in the Hawaii dataset, but could be acting in addition to magma mixing (Section 4.2). 
The predicted Fo- $T_{\text {crys }}$ pattern, i.e., a steepening of a single liquid line of descent (the orange line in Figure 5b), is also not seen in any of the other datasets we invert in Section 6 (Supplementary Figures S.2 and S.3). If crystals are derived from fractional crystallization of a single magma, the non-appearance of this pattern in natural data might reflect crystal scavenging on a significantly different length scale than the diffusion length scale. Whilst the datasets do not conform to the simplest permutation of diffusive homogenization, we think it unlikely that the olivine population mean is displaced significantly from its primary value (assuming diffusion is responsible for the decoupling); however, making this assumption does introduce unquantifiable uncertainty into the value of $T_{\text {crys }}^{\text {primary }}$ used for the $T_{p}$ inversions in Section 6 .

\subsection{Concurrent magma crystallization and mixing}

Olivine populations in Fo- $T_{\text {crys }}$ space can be bounded by two liquid lines of descent (LLD) (Figure 5c) each corresponding to a primary magma of distinct composition (Matthews et al., 2016). Pyroxenite-derived melts generally have a lower Mg\# and a higher FeO content than lherzolite-derived melts (e.g., Kogiso et al., 2004; Lambart et al., 2009; Jennings et al., 2016); therefore, they will saturate in olivine of lower Fo at the same temperature, compared to lherzolite-derived melts (Roeder \& Emslie, 1970). Since the lherzolitederived melts are the most likely to have been in equilibrium with $\mathrm{Fo}_{>91}$ olivine, the most suitable starting point for extrapolating back to $T_{\text {crys }}^{\text {primary }}$ is an olivine crystallized on the lherzolite-derived melt LLD. The lower bounding liquid line of descent in Fo- $T_{\text {crys }}$ space represents olivines crystallized from melts closest to the lherzolite-derived endmember, and so the termination of this LLD at Fo91 defines our estimate for $T_{\text {crys }}^{\text {primary }}$.

By assuming the apparent decoupling between Fo and $T_{\text {crys }}$ arises from primary magma heterogeneity, a lower $T_{\text {crys }}^{\text {primary }}$ estimate will be obtained than would be obtained by assuming a diffusive origin for the decoupling (Section 4.1). During crustal residence, magma diversity is gradually homogenised (A. Sobolev \& Shimizu, 1994; Saal et al., 1998; Maclennan, 2008; Shorttle, 2015; Shorttle et al., 2016), meaning the range in $T_{\text {crys }}$ should become tighter with decreasing Fo. Whilst the crystallization temperature dataset from Iceland is consistent with this (Figure 2 and Matthews et al., 2016), the same feature is not obvious in other datasets. The lack of a progressive mixing signal in these other datasets might be due to each spanning an insufficient range of olivine Fo, or the signal may have been modified by diffusive Fo re-equilibration.

\section{Modelling mantle melting}

Linking $T_{\text {crys }}^{\text {primary }}$ to mantle $T_{p}$ requires quantification of the latent heat of melting. To this end we employ a model for multi-lithologic adiabatic mantle melting which allows us to predict $T_{\mathrm{crys}}^{\text {primary }}$ for specified mantle $T_{p}$, pyroxenite fraction, $\phi_{\mathrm{px}}$, and harzburgite fraction, $\phi_{\mathrm{hz}}$. Using a melting model enables simultaneous prediction of observable proxies for magma productivity: crustal thickness at oceanic spreading centres and magma flux at ocean islands. Here we summarize the melting model and how it is applied to spreadingridge and intra-plate magmatism. In Section 6 we describe how we invert the model to estimate mantle $T_{p}$ and its uncertainty from $T_{\text {crys }}^{\text {primary }}$.

Our models are based on the generalized formulation by Phipps Morgan (2001) for calculating the melting behaviour of a multi-component mantle during adiabatic decompression. Any mantle lithology may be incorporated into this framework, provided expressions exist for the partial derivatives of temperature, $T$, with melt fraction, $F$, and pressure, $P$, $\left(\frac{\partial T}{\partial F}\right)_{P}$ and $\left(\frac{\partial T}{\partial P}\right)_{F}$ (the subscript indicates which parameter is kept constant), the entropy change on melting, $\Delta S$, the heat capacity, $C_{p}$ and density, $\rho$. The reader is referred to Phipps Morgan (2001) and Shorttle et al. (2014) for a full description of the model, and to Matthews et al. (2016) for a thorough characterization of its behaviour when predicting 
crystallization temperatures. Here we provide an overview of the most important features of the model, and how it is applied to mid-ocean ridge and intra-plate magmatism.

First, the geotherm through the melting region must be calculated. The path of the geotherm depends on the mantle $T_{p}$ and the melt fraction, which itself is controlled by $\phi_{\mathrm{px}}$ and $\phi_{\mathrm{hz}}$, and the properties of each lithology listed in the preceding paragraph. The forward model found to provide the best fit to the Hawaii $T_{\text {crys }}^{\text {primary }}$ is shown in Figure 6 . Prior to crossing its solidus, upwelling mantle follows the solid adiabat, loosing heat only to the work done during expansion. Once the mantle crosses the pyroxenite solidus it begins melting (blue line in Figure 6b), heat is extracted by the latent heat of melting, causing the mantle temperature to decrease more rapidly per unit of decompression. Upon further upwelling the mantle crosses the lherzolite solidus (purple line in Figure 6b), increasing the rate of melting, and causing the temperature to decrease more rapidly still. Following Shorttle et al. (2014) and Matthews et al. (2016), we assume the harzburgite fraction does not melt.

Melting ceases once the mantle reaches the base of the lithosphere (the tan-shaded region in Figure 6b), and the melt is extracted to a magma chamber (shown by the diamond symbol), which we assume to lie at the base of the crust. Whilst crystallization takes place throughout the crust (e.g. Cashman et al., 2017; Neave \& Putirka, 2017) and in the lithospheric mantle underlying the crust (e.g., Kelemen et al., 1997; Herzberg, 2004), the uncertainty this introduces is difficult to quantify, but we think it most likely that the primitive crystals we consider here crystallize close to the base of the crust. As no further melt is generated, and we assume the melt does not interact with the lithosphere, the rate of temperature change from this point follows the liquid adiabat. Finally, the temperature of olivine saturation is calculated. A magma will saturate at a temperature determined by both its composition and the pressure. Putirka (2008b) provides a simple expression (Eq. 15) for this relationship, modified from Helz and Thornber (1987). Following Matthews et al. (2016) we use the pressure dependence of this expression to extrapolate from the pressure and temperature at which a magma leaves the mantle, to the temperature at which it will begin to crystallise at lower pressure. If this saturation temperature is cooler than the temperature at which the melt arrives, the melt must lose heat before crystallizing olivine. This final step is not visible on Figure 6 as the temperature of olivine saturation is very close $\left(<10^{\circ} \mathrm{C}\right)$ to the temperature at which we predict the melts to arrive in the magma chamber.

The melt fraction of each lithology is calculated simultaneously with the geotherm (Figure 6c). The total melt fraction (grey in 6c) is lower than the melt fractions of the lherzolite and pyroxenite (blue and purple, respectively) since, in this solution, we find a considerable amount of non-melting harzburgite to be present.

When melting occurs at spreading-ridges by passive upwelling, the crustal thickness can be calculated directly from the total melt fraction, $F$, (White et al., 1992), without knowledge of the upwelling velocities or the detailed melting region geometry:

$$
t_{\text {crust }}=\frac{1}{\rho g} \int_{P_{0}}^{P_{l}} \frac{F}{1-F} d P,
$$

where $\rho$ is the density of crust, $g$ is the gravitational acceleration, and $P_{l}$ and $P_{0}$ are the pressures at the base of the lithosphere and onset of melting, respectively. The contribution of pyroxenite-derived melts to the volume of the crust can be calculated using a similar expression:

$$
X_{\mathrm{px}}=\frac{\int_{P_{0}}^{P_{l}} \frac{F_{\mathrm{px}}}{1-F} d P}{\int_{P_{0}}^{P_{l}} \frac{F}{1-F} d P},
$$

where $F_{\mathrm{px}}$ is the melt fraction of the pyroxenite.

In settings where mantle decompression is caused by plume-driven (active) upwelling, melt thicknesses or fluxes can be calculated, provided the mantle upwelling velocity and 

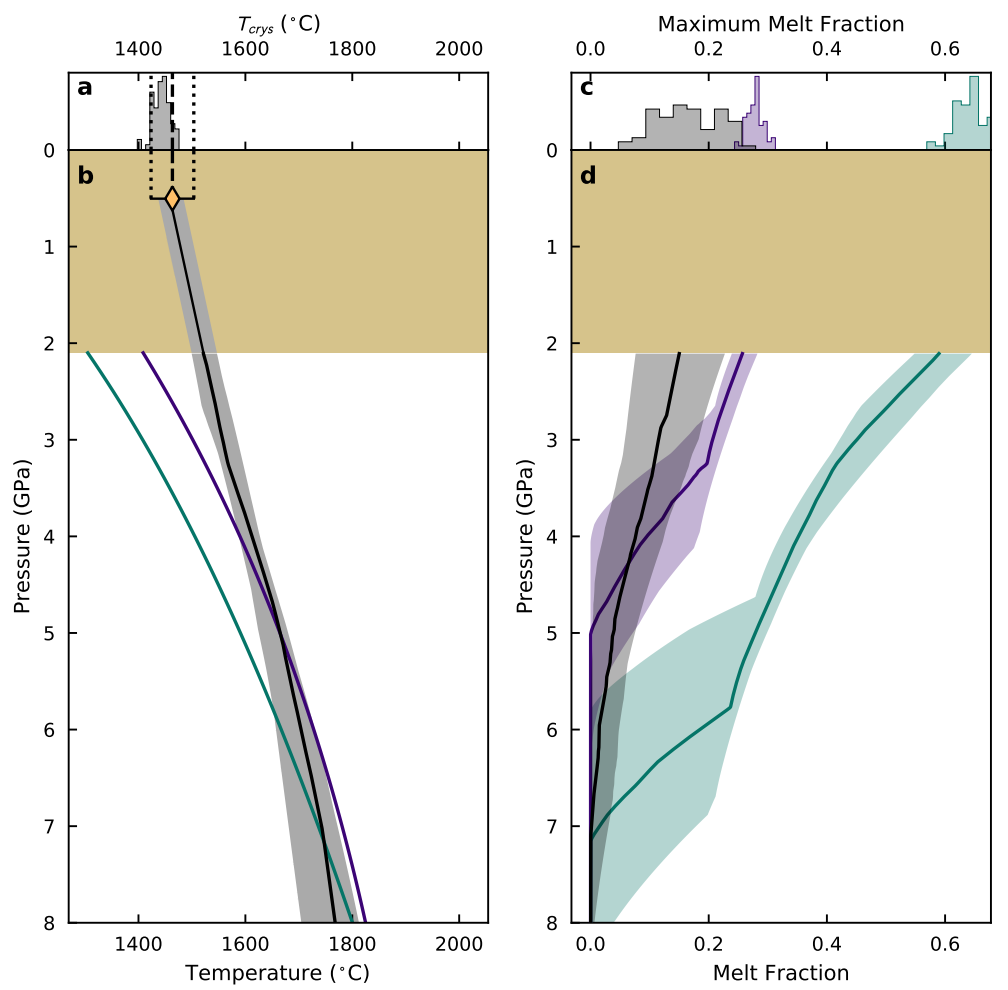

Figure 6. Illustration of the forward models representing the median and $95 \%$ confidence intervals for Hawaii, found by inverting $T_{\text {crys }}^{\text {primary }}$ and magma flux, $Q_{m}$. Panel a shows the distribution of crystallization temperatures recovered from the inversion results. Panel b shows the thermal structure of the melting region. The lherzolite and pyroxenite solidii are shown by the purple and blue lines. Panel c shows the distribution of maximum lherzolite (purple), pyroxenite (green-blue) and total mantle melt (grey) fractions. The total melt fraction may be less than both the lherzolite and pyroxenite melt fractions when (non-melting) harzburgite is included in the calculation. Panel $\mathrm{d}$ shows the evolution with pressure of each lithology's melt fraction. In both panels $\mathrm{b}$ and $\mathrm{d}$, the lithosphere is shown by the the tan shading. The diamond symbol and error bars in panel b show the value of $T_{\text {crys }}^{\text {primary }}$ estimated with the diffusive end-member correction (Section 4.1), placed at the pressure corresponding to the base of the crust. Note that the geotherms and melt fractions vs depth curves are shown for fixed lithosphere thickness and magma chamber depths, in reality each solution has its own lithosphere thickness and magma chamber depth, their distribution controlled by their uncertainties. 
melting region geometry is known. Shorttle et al. (2014) made the simplifying assumption that plume flow approximates flow through a deformable conduit, applying the expression from Turcotte and Schubert (2014):

$$
Q_{v}=\frac{\pi}{8} \frac{\Delta \rho g r^{4}}{\mu_{p}}
$$

where $Q_{v}$ is the volume flux of mantle, $\Delta \rho$ is the density difference between the mantle plume and ambient mantle, $g$ is the gravitational acceleration, $r$ is the conduit radius, and $\mu_{p}$ is the viscosity of the plume. In applying this equation we are neglecting the effect of the overlying lithosphere on the velocity field of the upwelling mantle: by the time the plume material reaches the base of the lithosphere its vertical velocity must be zero. Our approach will, therefore, lead to us over-estimating melt production, as a non-diminishing upwelling velocity will cause more decompression melting than the real case. Increased melt production means a greater amount of heat is extracted by melting; consequently, melts will leave the mantle and crystallise at a lower temperatures. This simplification means our inversion results will be biased towards slightly higher values of $T_{p}$ in locations where we constrain the results using magmatic flux.

$\Delta \rho$ is taken to be the density difference at $80 \mathrm{kbar}$, and is calculated from the weighted average of the lithology densities at the appropriate $T_{p}$. The density of each lithology is calculated using THERMOCALC v3.40 (Powell et al., 1998) with the dataset from Holland and Powell (2011) and the solution models by Jennings and Holland (2015). The value of $\mu_{p}$ is set to $10^{19} \mathrm{Pas}$ as a conservative, low, estimate of mantle viscosity (Shorttle et al., 2014), biasing the inversion towards predicting high volume fluxes, lower $F$, and therefore lower mantle $T_{p}$. To convert the plume volume flux to a melt flux $Q_{m}$, we multiply $Q_{v}$ by the total melt fraction at the top of the melting region, assuming the densities of solid and melt are comparable within the uncertainties of the calculation.

Modelling the highest values of mantle $T_{p}$ inferred throughout Earth's history (e.g., the Galápagos plume-related lavas studied by Alvarado et al., 1997; Trela et al., 2017) and characterising the high $T_{p}$ tail of the inverted $T_{p}$ probability distributions (Section 6 ), requires melting at pressures far in excess of $10 \mathrm{GPa}$. The models presently available for lherzolite melting (e.g., Katz et al., 2003; Hirschmann, 2000; Herzberg et al., 2000) and pyroxenite melting (e.g., Shorttle et al., 2014; Lambart et al., 2016; Pertermann \& Hirschmann, 2003) are typically calibrated on experiments run at pressures of $10 \mathrm{GPa}$ and lower. Even if the expressions were to be extrapolated beyond their calibrated range, the use of quadratic functional forms for the solidus and liquidus (e.g., Katz et al., 2003; Shorttle et al., 2014) means extrapolation rapidly becomes not only inaccurate, but unphysical, as melting pressures exceed the stationary points of the functions.

To enable us to model high values of mantle $T_{p}$ we take two approaches. First, we calibrate new parameterizations of lherzolite and pyroxenite melting suitable for calculations up to at least $10 \mathrm{GPa}$. In Supporting Text S2, we provide models for melting of the silica-undersaturated pyroxenite KG1, a silica-oversaturated pyroxenite, and KLB-1 lherzolite. Putirka et al. (2007) and Putirka (2016) also took this approach to calculating melting behaviour at high pressures, calibrating new functions for the lherzolite liquidus and solidus. Whilst the Katz et al. (2003) parameterization for lherzolite melting can be used at pressures up to $10 \mathrm{GPa}$, a wide range of peridotite compositions is used in its calibration, including silica-undersaturated pyroxenites, which we model here as a separate lithology. In all the inversions in Section 6, we use the silica-undersaturated pyroxenite as the pyroxenite endmember. Secondly, we introduce an isobaric melting step for calculations where the solidus is intersected at pressures greater than $10 \mathrm{GPa}$, the expressions for which are provided in Supporting Text S5. 


\section{Inverse model}

The forward model allows us to predict the value of $T_{\text {crys }}^{\text {primary }}$ for given values of mantle $T_{p}, \phi_{\mathrm{px}}, \phi_{\mathrm{hz}}$, lithosphere thickness and magma chamber depth. However, it is the inverse calculation that is of most interest, i.e., predicting the value of $T_{p}$ given an observation of $T_{\text {crys }}^{\text {primary }}$, subject to the uncertainties of the other parameters. For some localities we have additional observations which can constrain mantle $T_{p}$ : the crustal thickness $t_{\text {crust }}$ at mid-ocean ridges, equivalently the magmatic flux, $Q_{m}$, at intra-plate volcanic centres, and the fraction of pyroxenite derived melt $X_{\mathrm{px}}$. The parameters $t_{\text {crust }}, Q_{m}$, and $X_{\mathrm{px}}$ can be simultaneously calculated from the forward model (Section 5).

To find the set of solutions which can reproduce $T_{\text {crys }}^{\text {primary }}$, and other constraints where applicable, we use a Bayesian Monte Carlo inversion routine, summarised in Figure 1. A large number of forward models are run with values for each required parameter chosen according to the prior probability distributions we define. The fit of each model to the data is assessed with the log-likelihood function, $\ln (L)$, and the estimates of all the model parameters are refined. This process is repeated until the maximum likelihood region is sufficiently characterized for estimation of the posterior probability distributions of each parameter. We implement the MultiNest Monte Carlo nested sampling algorithm (Feroz \& Hobson, 2008; Feroz et al., 2009, 2013) using the pyMultiNest wrapper (Buchner et al., 2014).

For each parameter $x$ that the inversion is required to match, the contribution to the log-likelihood is given by:

$$
\ln (L)=\sum_{x} \ln \left(L_{x}\right)
$$

$$
\ln \left(L_{x}\right)=-\frac{1}{2} \ln \left(2 \pi \sigma_{x}^{2}\right)-\frac{\left(x_{\mathrm{obs}}-x_{\mathrm{calc}}\right)^{2}}{2 \sigma_{x}^{2}},
$$

where $x_{\text {obs }}$ is the observed value, $\sigma_{x}$ is its standard deviation, and $x_{\text {calc }}$ is the value predicted by the forward model.

Whilst it is possible, in principle, to match the observations of $T_{\text {crys }}^{\text {primary }}, t_{\text {crust }}$, and $Q_{m}$ with extremely high fractions of pyroxenite, in such a scenario the mantle is unlikely to be buoyant with respect to the ambient mantle (Shorttle et al., 2014). Where intraplate magmatism is thought to be generated within a buoyantly rising mantle plume, such solutions are not physically realistic. To prevent negatively buoyant solutions contributing to the posterior probability distributions, we modify the likelihood function when $\rho_{\text {plume }}>$ $\rho_{\text {ambient: }}$ :

$$
\ln \left(L_{\text {buoyancy }}\right)=\ln (L)-\left(\exp \left(\rho_{\text {plume }}-\rho_{\text {ambient }}\right)-1\right),
$$

where the density difference is calculated at $80 \mathrm{kbar}$.

In addition to Hawaii, we apply the same inversion to a number of locations with published olivine-spinel aluminum-exchange $T_{\text {crys }}$ estimates, the literature sources of which are shown in Table 1. We only include locations where estimates of the lithospheric thickness at the time of the igneous activity have been made. We also repeat the calculations made by Matthews et al. (2016) for Iceland and Siqueiros using our new parameterizations of mantle melting and data from Siqueiros.

Following Matthews et al. (2016), we use the crustal thickness at Iceland's coast to further constrain mantle $T_{p}$. Though Iceland lies above a mantle plume, Maclennan et al. (2001) demonstrated that active mantle-upwelling is not required to explain the composition or volume of magmatism at Iceland's coasts. The Icelandic melting region may, therefore, be treated as passive upwelling beneath a mid-ocean ridge. We also use $X_{\mathrm{px}}$ for both Iceland and Siqueiros, which have estimated $X_{\mathrm{px}}$ from magma chemistry (Shorttle et al., 2014; Hirschmann \& Stolper, 1996). We do not use $X_{\mathrm{px}}$ to constrain solutions for the intra-plate settings, as its value is very sensitive to assumptions about melting region geometry. 


\begin{tabular}{|c|c|c|c|c|c|c|}
\hline Location & $T_{\text {crys }}^{*}\left({ }^{\circ} \mathrm{C}\right)$ & $t_{\text {lith }}(\mathrm{km})$ & $t_{\text {crust }}(\mathrm{km})$ & $X_{\mathrm{px}}$ & $Q_{m}\left(\mathrm{~m}^{3} \mathrm{~s}^{-1}\right)$ & refs \\
\hline Hawaii (diff.) & $1464 \pm 20^{\mathrm{a}}$ & $75 \pm 5$ & $18 \pm 1$ & & $10 \pm 2$ & $1,2,3,4$ \\
\hline Hawaii (het.) & $1419 \pm 20^{\mathrm{a}}$ & $75 \pm 5$ & $18 \pm 1$ & & $10 \pm 2$ & $1,2,3,4$ \\
\hline Iceland & $1383 \pm 22$ & - & $20 \pm 1$ & $0.3 \pm 0.1$ & & $5,6,7$ \\
\hline Siqueiros & $1280 \pm 20$ & - & $5.74 \pm 0.27$ & $0.175 \pm 0.1$ & & $1,8,9$ \\
\hline \multicolumn{7}{|c|}{ North Atlantic Igneous Province } \\
\hline Rum & $1462 \pm 22$ & $70 \pm 5$ & $28 \pm 2$ & & & $10,11,12$ \\
\hline Skye & $1465 \pm 22$ & $70 \pm 5$ & $28 \pm 2$ & & & $10,11,12$ \\
\hline Mull & $1400 \pm 22$ & $70 \pm 5$ & $28 \pm 2$ & & & $10,11,12$ \\
\hline Baffin & $1413 \pm 22$ & $60 \pm 5$ & $35 \pm 1$ & & & $10,13,14$ \\
\hline SE Greenland & $1398 \pm 22^{\mathrm{a}}$ & $60 \pm 5$ & $27 \pm 2$ & & & $15,11,16$ \\
\hline W Greenland & $1421 \pm 22$ & $60 \pm 5$ & $33 \pm 2$ & & & $10,13,16$ \\
\hline \multicolumn{7}{|c|}{ Caribbean Large Igneous Province } \\
\hline Curaçao & $1353 \pm 20^{\mathrm{a}}$ & $60 \pm 10$ & $30 \pm 5^{\mathrm{b}}$ & & & 17,18 \\
\hline Gorgona & $1403 \pm 22$ & $60 \pm 10$ & $30 \pm 5^{\mathrm{b}}$ & & & 15,18 \\
\hline Tortugal & $1578 \pm 20$ & $60 \pm 10$ & $30 \pm 5^{\mathrm{b}}$ & & & 17,18 \\
\hline \multicolumn{7}{|c|}{ Other Large Igneous Provinces } \\
\hline Karoo & $1471 \pm 35$ & $45 \pm 5$ & $30 \pm 5^{\mathrm{b}}$ & & & 19,11 \\
\hline Emeishan & $1438 \pm 32$ & $60 \pm 5$ & $30 \pm 5^{\mathrm{b}}$ & & & 20,21 \\
\hline Etendeka & $1469 \pm 24$ & $50 \pm 10$ & $20 \pm 2$ & & & $22,23,24$ \\
\hline
\end{tabular}

Table 1. References: 1. This study. 2. Putirka (1999); Bock (1991). 3. Watts and Ten Brink (1989). 4. Wessel (2016). 5. Matthews et al. (2016). 6. Darbyshire et al. (2000). 7. Shorttle et al. (2014). 8. Aghaei et al. (2014). 9. Hirschmann and Stolper (1996). 10. Spice et al. (2016). 11. White and $\mathrm{M}^{\mathrm{c}}$ Kenzie (1995). 12. Davis et al. (2012). 13. Gill et al. (1992). 14. Gilligan et al. (2016). 15. Coogan et al. (2014). 16. Kumar et al. (2007). 17. Trela et al. (2017). 18. Kerr (2005). 19. Heinonen et al. (2015). 20.R. Xu and Liu (2016). 21. Y. Xu et al. (2001). 22. Jennings et al. (2019). 23. Thompson and Gibson (2000). 24. Thompson et al. (2001). ${ }^{*}$ The values for $T_{\text {crys }}$ shown here are for the inversions shown in Figure 7, a full list of the $T_{\text {crys }}$ values used in all inversions is

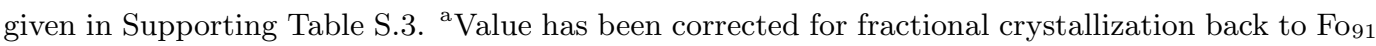
using the diffusion correction, unless indicated. ${ }^{\mathrm{b}}$ Since the lavas are located on accreted terrains, and the inversion is very weakly sensitive to $t_{\text {crust }}$, a value is assumed.

The only location where $Q_{m}$ is used to constrain the solution is Hawaii, as there is little constraint on the geometry of the melting region beneath LIPs at the time of their formation. Hence, we choose values for the plume conduit radius appropriate for Hawaii: between 50 and $300 \mathrm{~km}$. These bounds are derived from the dynamic models of the Hawaiian plume by Watson and $\mathrm{M}^{\mathrm{C}}$ Kenzie (1991); the lower bound corresponding to the radius of the melting region, and the upper bound to the radius of plume-driven upwelling. This range of values propagates both the uncertainty associated with the dynamic models, and the uncertainty generated by assuming the radial temperature field is uniform.

The lithosphere thickness, $t_{\text {lith }}$, determines when melting ceases. For the North Atlantic Igneous Province we use estimates made by Hole and Millett (2016) using the PRIMELT3 algorithm (Herzberg \& Asimow, 2015). For both Rum and Skye, Hole and Millett (2016) calculate two different final melting pressures. We use the higher of the two estimates for both locations as the samples for which thermometry was performed come from early in the magmatic activity, when the lithosphere was likely to be at its thickest. The base of 
the lithosphere for Iceland and MORB is taken as the base of the crust, calculated by the model. The priors for $t_{\mathrm{lith}}$ and the magma storage pressure (taken to be the base of the crust, $\left.t_{\text {crust }}\right)$ are normal distributions defined by their estimated value and its uncertainty (Table 1).

The priors set on $\phi_{\mathrm{px}}$ and $\phi_{\mathrm{hz}}$ are both uniform distributions from 0 to 1 . Though this provides a uniform probability distribution over $\phi_{\mathrm{lz}}-\phi_{\mathrm{px}}-\phi_{\mathrm{hz}}$ space, half of the solutions (where $\phi_{\mathrm{px}}+\phi_{\mathrm{hz}}>1$ ) are not physical. A crude, but effective, approach we adopt to prevent such unphysical solutions, is to return the following log-likelihood value when $\phi_{\mathrm{Px}}+\phi_{\mathrm{Hz}}>1$ :

$$
\ln (L)=-10^{10} \exp \left(1+\phi_{\mathrm{Px}}+\phi_{\mathrm{Hz}}\right)
$$

For locations with Fo $>91_{1}$ olivine crystals, we use the mean of the high $T_{\text {crys }}$ population as our estimate for $T_{\text {crys }}^{\text {primary }}$, shown in Supplementary Figures S.2 and S.3. Where locations lack $\mathrm{Fo} \geq 91$ olivine crystals, we apply the correction methods described in Section 4. Inversions are run using $T_{\text {crys }}^{\text {primary }}$ estimates derived from both correction schemes, in addition to the uncorrected mean $T_{\text {crys }}$. The parameters used in the correction calculations, and their results, are shown in Supporting Table S.3. Table 1 shows only the $T_{\text {crys }}^{\text {primary }}$ estimates derived from the diffusive correction.

\section{Inversion results and discussion}

The values of mantle $T_{p}$ calculated for Hawaii and the other locations in our compilation are summarized in Figure 7 and Table 2. The best fit geotherms and melt fractions for each locality are shown in Supporting Figures S.6 to S.22. The marginal likelihood distributions are shown in Supporting Figures S.23 to S.41, and summarised in Supporting Table S.4. Values of $t_{c}, X_{\mathrm{Px}}$, and $Q_{m}$ calculated from the posterior distributions are shown in Supporting Figures S.42 to S.45, the values of $T_{\text {crys }}^{\text {primary }}$ calculated from the posterior distributions are shown in Supporting Figures S.6 to S.22, and are all summarised in Supporting Table S.5. In all cases, the constraints are adequately reproduced by the posterior distributions.

All plume localities, except Curaçao, have mantle $T_{p}$ significantly higher than MORB (Siqueiros, $1364_{-23}^{+23 \circ} \mathrm{C}$ ). Whilst there is substantial variability in maximum-likelihood $T_{p}$ among plume locations, most of the posterior distributions overlap with the Iceland posterior distribution. The posterior $T_{p}$ distribution for Tortugal is an exception to this, suggesting that crystallization temperatures do, most likely, record variable mantle plume $T_{p}$. Figure 8 allows assessment of whether our choices of lithosphere thickness $t_{\text {lith }}$, magma chamber depth $t_{\text {crust }}$, and $T_{\text {crys }}^{\text {primary }}$ introduce systematic biases into our $T_{p}$ estimates. No co-variation between these variables and $T_{p}$ is observed, save for $T_{\text {crys }}^{\text {primary }}$, implying our choices of $t_{\text {lith }}$ and $t_{\text {crust }}$ do not systematically bias our results.

The strong covariation of $T_{\text {crys }}^{\text {primary }}$ with $T_{p}$ (Figure 8a) demonstrates the median of the posterior $T_{p}$ distribution is primarily controlled by $T_{\text {crys }}^{\text {primary }}$. The strong correlation between $T_{\text {crys }}^{\text {primary }}$ and $T_{p}$ might suggest direct comparison of $T_{\text {crys }}^{\text {primary }}$ will yield meaningful insights into mantle $T_{p}$ variation without further modelling. However, the uncertainty on the $T_{p}$ estimates encompasses much of the inter-plume variation. Since much of this uncertainty is propagated from uncertainty in $\phi_{\mathrm{px}}$ and $\phi_{\mathrm{hz}}$, only where $\phi_{\mathrm{px}}$ and $\phi_{\mathrm{hz}}$ are thought to be comparable between two locations, will a direct comparison of $T_{\text {crys }}^{\text {primary }}$ be meaningful.

Siqueiros (MORB) and Iceland fall off the main trend in Figure 8a, confirming that tectonic setting plays an important role in determining $T_{\text {crys }}$. The ability of the mantle to upwell to much shallower levels at mid-ocean ridges than in intra-plate settings means a greater melt fraction can be achieved, more heat is extracted during melting, and melts crystallize at systematically lower $T_{\text {crys }}$. Consequently, caution must be exercised when comparing intra-plate raw $T_{\text {crys }}$ values to MORB or Iceland. 


\begin{tabular}{lccc}
\hline Location & $\begin{array}{c}\text { High } T_{\text {crys }} / \text { Fog1 }_{91} \\
\text { population }\left({ }^{\circ} \mathrm{C}\right)\end{array}$ & Diffusion $\left({ }^{\circ} \mathrm{C}\right)$ & Magma Het. $\left({ }^{\circ} \mathrm{C}\right)$ \\
\hline Hawaii (magma flux) & $1402_{-45}^{+69}$ & $1582_{-65}^{+68}$ & $1516_{-59}^{+67}$ \\
Hawaii & - & $1592_{-80}^{+66}$ & $1522_{-77}^{+77}$ \\
Iceland & $1525_{-18}^{+21}$ & - & - \\
Siqueiros (MORB) & $1364_{-23}^{+23}$ & - & - \\
\hline
\end{tabular}

North Atlantic Igneous Province

\begin{tabular}{lrcc} 
Rum & $1556_{-65}^{+75}$ & - & - \\
Skye & $1566_{-70}^{+73}$ & - & - \\
Mull & $1462_{-58}^{+77}$ & - & - \\
Baffin & $1496_{-75}^{+71}$ & - & - \\
W Greenland & $1487_{-60}^{+87}$ & - & $1464_{-66}^{+71}$ \\
SE Greenland & $1397_{-52}^{+89}$ & $1488_{-72}^{+70}$ & $1381_{-50}^{+84}$ \\
\hline Caribbean Large Igneous & Province & & - \\
Curaçao & $1279_{-23}^{+34}$ & $1408_{-58}^{+84}$ & - \\
Gorgona & $1492_{-67}^{+78}$ & - & \\
Tortugal & $1813_{-149}^{+157}$ & - &
\end{tabular}

Other Large Igneous Provinces

$\begin{array}{ll}\text { Emeishan } & 1555_{-97}^{+100} \\ \text { Karoo } & 1601_{-103}^{+193} \\ \text { Etendeka } & 1599_{-79}^{+104}\end{array}$

Table 2. $\quad T_{p}$ estimates calculated using either raw $T_{\text {crys }}$ values (first column), or using $T_{\text {crys }}^{\text {primary }}$ values derived using the correction schemes derived in Section 4 . The values quoted are the medians of the posterior $T_{p}$ distributions, and the uncertainties are their $5^{\text {th }}$ and $95^{\text {th }}$ percentiles. 


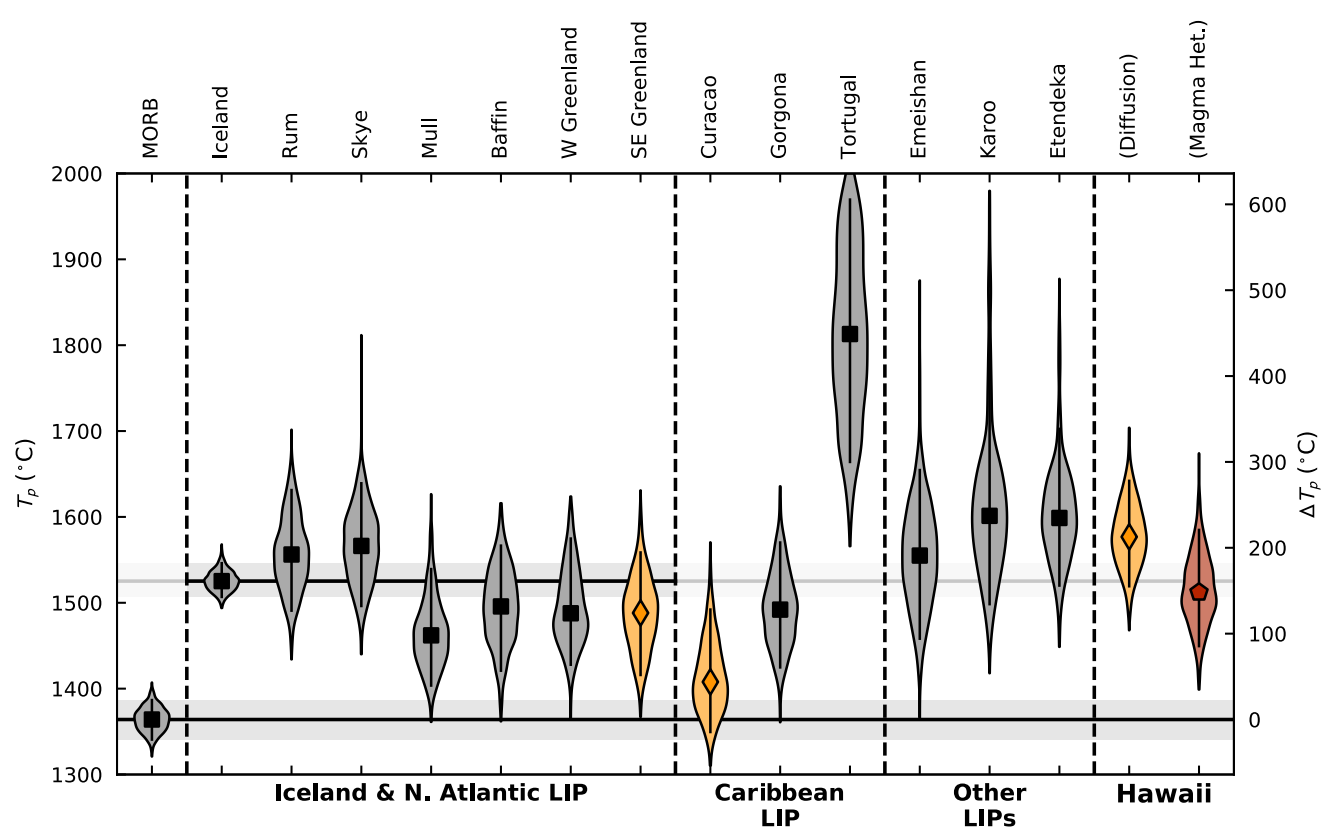

Figure 7. Estimates of mantle potential temperature $\left(T_{p}\right)$ derived from the means of the high $T_{\text {crys }}$ populations seen in each location (black squares and grey histograms), or from applying the correction method assuming diffusive Fo and $T_{\text {crys }}$ decoupling (orange diamonds and histograms). The right-hand axis shows the $T_{p}$ offset relative to the median MORB (Siqueiros) $T_{p}$ estimate. The horizontal lines show the median $T_{p}$ estimates for MORB (Siqueiros) and Iceland; the grey shading shows their $5^{\text {th }}$ and $95^{\text {th }}$ percentiles. For Hawaii, the $T_{p}$ estimate from applying the magmaheterogeneity correction scheme is shown (red pentagon and histogram). The inversion results shown for Hawaii satisfy the observed magma flux. Error bars show the $5^{\text {th }}$ and $95^{\text {th }}$ percentiles.
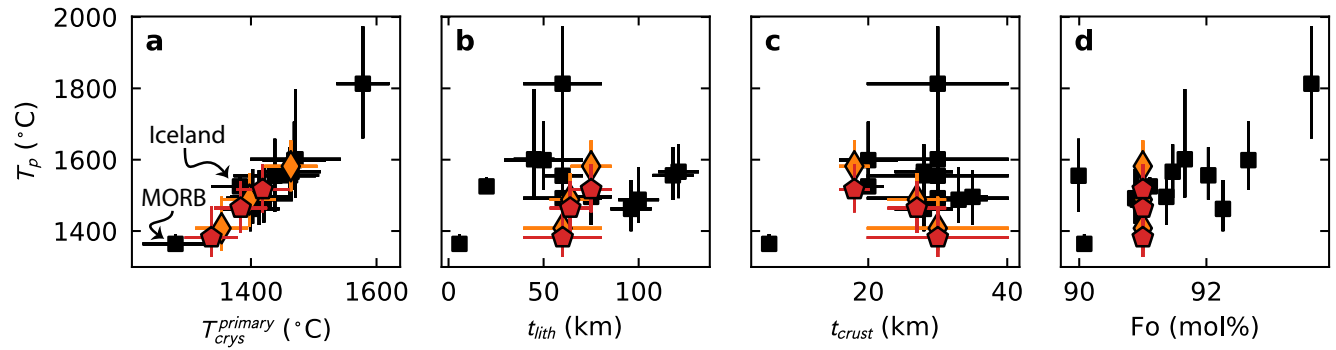

Figure 8. Estimates of mantle potential temperature $\left(T_{p}\right)$ compared to the primary crystallization temperature $\left(T_{\text {crys }}^{\text {primary }}\right)$, the lithospheric thickness $\left(t_{\text {lith }}\right)$, and crustal thickness $\left(t_{\text {crust }}\right)$ used in the inversions (panels a, b and c). Also shown (panel d) is the relationship between $T_{p}$ estimate and olivine composition from which $T_{\text {crys }}^{\text {primary }}$ is derived. Symbols distinguish whether the crystallization temperature used in each inversion was the average of the high temperature population (black squares), or corrected back to Fo91 (orange diamonds for the diffusive $T_{\text {crys }}^{\text {primary }}$ correction, and red pentagons for the magma-heterogeneity $T_{\text {crys }}^{\text {primary }}$ correction). 


\subsection{Siqueiros (MORB)}

A consequence of using our new parameterizations of mantle melting (Supporting Text S2) is a systematic shift to higher estimates of mantle $T_{p}$ when compared with the calculations by Matthews et al. (2016). In this study we calculate a mantle $T_{p}$ for Siqueiros of $1364_{-23}^{+23 \circ} \mathrm{C}$, higher but within error of $1318_{-32}^{+44 \circ} \mathrm{C}$ calculated by Matthews et al. (2016). In addition to the systematic shift towards higher mantle $T_{p}$, we also used a higher value of $T_{\text {crys }}^{\text {primary }}$, derived from our new measurements (Section 3 ). This systematic offset highlights the importance of making comparisons between mantle $T_{p}$ estimates derived using the same models.

We report a lower uncertainty on the Siqueiros mantle $T_{p}$ than Matthews et al. (2016), a consequence of taking a more robust Bayesian approach to parameter estimation. The uncertainty on our estimate of Siqueiros mantle $T_{p}$, alongside the uncertainty on our estimate for Iceland, is much lower than the other locations for which we estimate $T_{p}$. This much smaller uncertainty originates from the tight constraint crustal thickness places on the total melt fraction at mid-ocean ridges. The small uncertainty estimate does not include uncertainty in the melting models themselves; model uncertainty will affect all inversion results systematically. Such systematic uncertainty is of little consequence when considering the relative differences in mantle $T_{p}$. We also neglect uncertainty in application of the thermometer, i.e. the uncertainty in how close to equilibrium the olivine and spinel are, as this is difficult to quantify.

\subsection{Iceland}

As for Siqueiros, our new estimate of the Icelandic mantle $T_{p}\left(1525_{-18}^{+21 \circ} \mathrm{C}\right)$ differs from the $T_{p}$ estimated by Matthews et al. (2016) $\left(1480_{-30}^{+37 \circ} \mathrm{C}\right)$, but they are within mutual uncertainty. Our new inversions suggest a lower value of $\phi_{\mathrm{Hz}}$, but it is still significant, and in part reflects the more refractory nature of our new parameterization for lherzolite melting. As discussed by Matthews et al. (2016) the relative temperature offset between Iceland and Siqueiros agrees well with many previous studies, despite the inclusion of lithological heterogeneity in our models.

Figure $9 \mathrm{~b}$ demonstrates a small positive trade-off between $T_{p}$ and $\phi_{\mathrm{hz}}$, the opposite sense to that seen for Hawaii (Figure $9 \mathrm{e}$ and $\mathrm{h}$ ). While increasing the value of $\phi_{\mathrm{hz}}$ reduces the temperature drop during melting, it also decreases the total melt fraction. The inversion for Iceland is constrained particularly tightly by the requirement to produce a $20 \mathrm{~km}$ thick crust, any increase in $\phi_{\mathrm{hz}}$ must be compensated by an increase in $T_{p}$ to maintain a sufficiently high total melt fraction.

For a full discussion of how our $T_{p}, \phi_{\mathrm{px}}$, and $\phi_{\mathrm{hz}}$ estimates for Iceland compare to previous studies, the reader is referred to Matthews et al. (2016). A recent study by Brown et al. (2020a) takes a similar approach to estimating $T_{p}$ and $\phi_{\mathrm{px}}$ as applied here, albeit without matching a $T_{\text {crys }}^{\text {primary }}$ constraint. Rather than matching an imposed value of the relative proportion of pyroxenite- and lherzolite-derived melts, $X_{\mathrm{px}}$, as we do (following Matthews et al., 2016; Shorttle et al., 2014), they match the full suite of trace element concentrations directly. Brown et al. (2020a) find no requirement for a harzburgite component in the source, which is discussed further by Shorttle et al. (2020) and Brown et al. (2020b). As shown in Figure 10 of Matthews et al. (2016), a significant harzburgite fraction is required in the mantle source even in the absence of an $X_{\mathrm{px}}$ constraint. As in the models by Matthews et al. (2016), we require a significant harzburgite fraction to simultaneously match crustal thickness and crystallization temperature. Since the Brown et al. (2020a) model does not attempt to match $T_{\text {crys }}^{\text {primary }}$, they do not require a harzburgite fraction. Our inversions suggest $T_{p}$ is slightly higher than the inversions by Brown et al. (2020a), though we find a similar $\Delta T_{p}$ (relative to MORB). The difference between our (absolute) $T_{p}$ estimate and the $T_{p}$ estimate by Brown et al. (2020a) is due, in part, to the trade-off we see between $T_{p}$ and $\phi_{\mathrm{hz}}$ (Figure $9 \mathrm{~b}$ ), and partly due to differences in the fusibility of our lherzolite melting 

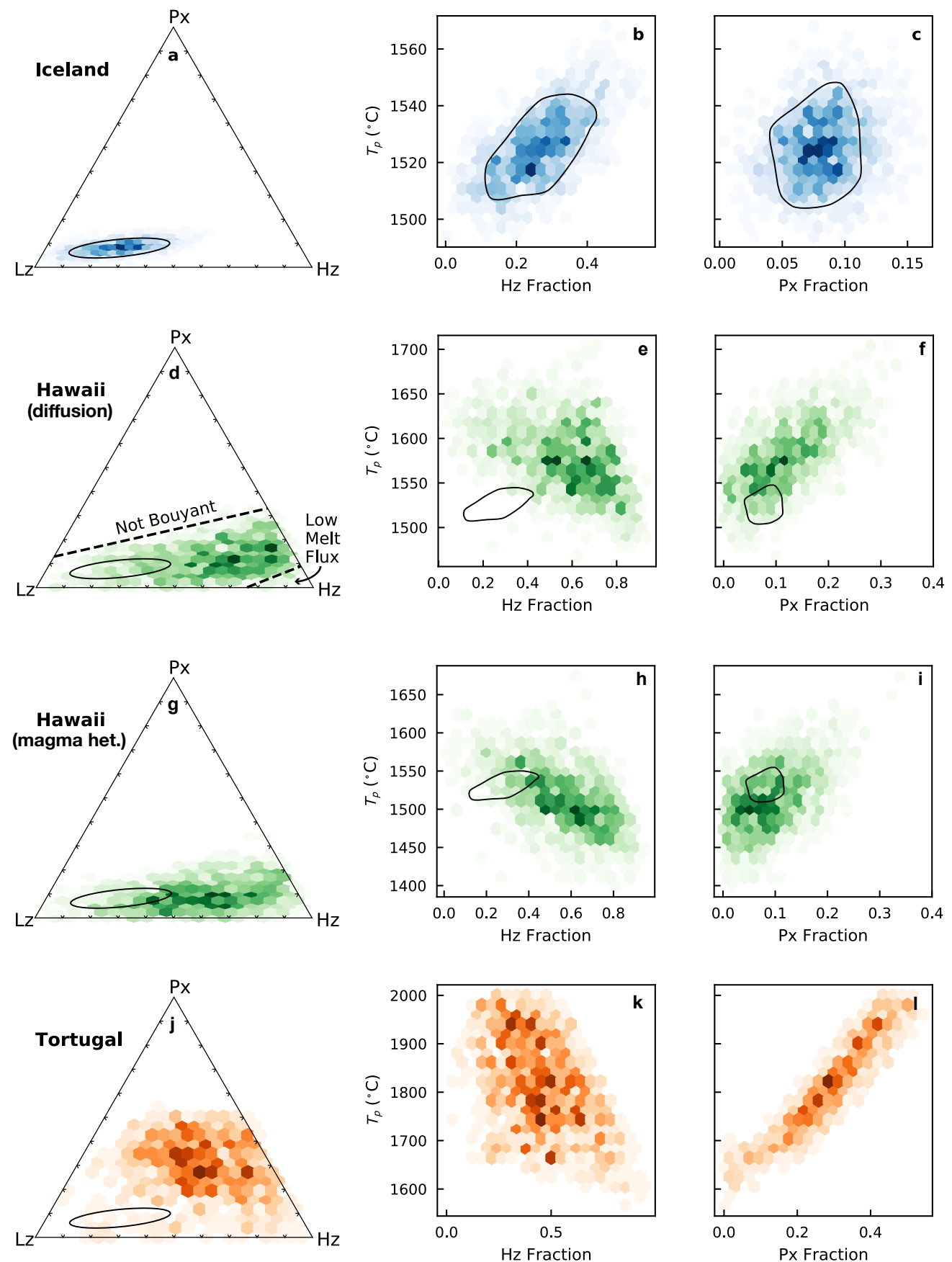

Figure 9. Posterior distributions for Iceland (a-c), Hawaii (d-i) and Tortugal (j-l) for mantle $T_{p}, \phi_{\mathrm{px}}$, and $\phi_{\mathrm{hz}}$. For Hawaii, results are shown for inversions using $T_{\mathrm{crys}}^{\text {primary }}$ estimates derived from both the diffusion correction and magma-heterogeneity correction methods. The annotations in panel a show the regions of parameter space in which solutions are prevented, on the basis of not producing a buoyant mantle plume, or being unable to match the observed magma flux. The shading shows the probability density. The black outline on plots a-i shows the approximate region of highest probability density for Iceland. 
models. However, our estimate of $\phi_{\mathrm{px}}(8 \pm 3 \%)$ is comparable to the $6.5-8.5 \%$ estimated by Brown et al. (2020a).

\subsection{Hawaii}

Here we summarise the results of the inversions for Hawaii, consider the effects each constraint has on the estimated $T_{p}$, and compare our $T_{p}$ estimates to previous $T_{p}$ estimates made for Hawaii.

\subsubsection{The effects of different choices of T $T_{\text {crys }}^{\text {primary }}$}

In Figure 7 we show the posterior mantle $T_{p}$ distributions for Hawaii, calculated using values of $T_{\text {crys }}^{\text {primary }}$ estimated with both the diffusive and magma-heterogeneity correction methods. The lower of the two mantle $T_{p}$ estimates is based on the magma-heterogeneity correction, and falls close to the $T_{p}$ we estimate for Iceland. The higher mantle $T_{p}$ estimate is derived from the diffusive correction, but still overlaps with the Iceland posterior mantle $T_{p}$ distribution. Both estimates demonstrate a robust elevation in Hawaiian $T_{p}$ relative to Siqueiros (MORB).

Whilst the assumptions we make in obtaining a value for $T_{\text {crys }}^{\text {primary }}$ clearly have a large impact on the estimated mantle $T_{p}$, applying no correction to $T_{\text {crys }}$ significantly decreases the estimated $T_{p}$ to being not far in excess of Siqueiros (Figure 10). Such a small temperature excess over ambient mantle is in clear contradiction of other observations that are not formally included in the inversion (e.g., Watson \& M $^{\mathrm{c}}$ Kenzie, 1991; Watson, 1993), further reinforcing that comparison of $T_{\text {crys }}$ is best made between the most primitive olivine crystals.

\subsubsection{Effect of applying the $Q_{m}$ constraint}

Figure 10 shows the small effect that imposing the $Q_{m}$ constraint (Wessel, 2016) has on the posterior mantle $T_{p}$ distributions. Requiring the models to produce a sufficient melt flux prevents solutions with the most extreme $\phi_{\mathrm{hz}}$ (Figure $9 \mathrm{~d}$ ). Since the solutions with the largest $\phi_{\mathrm{hz}}$ produce the smallest correction for the latent heat of melting (Matthews et al., 2016 ), the lowest $T_{p}$ solutions are no longer viable (Figure 10). $Q_{m}$ provides a much weaker constraint on the Hawaii mantle $T_{p}$ than $t_{\text {crust }}$ provides for Siqueiros and Iceland because we set a wide prior on the plume conduit radius (Section 5).

\subsubsection{Posterior constraints on $\phi_{p x}$ and $\phi_{h z}$}

Unlike the inversions for Siqueiros and Iceland, little constraint is placed on $\phi_{\mathrm{px}}$ and $\phi_{\mathrm{hz}}$ for Hawaii. On the basis of olivine Ni contents A. V. Sobolev et al. (2005) suggested the Hawaiian mantle is olivine-free; however, further experimental work has cast doubt on this conclusion (Wang \& Gaetani, 2008; Niu et al., 2011; Matzen et al., 2017). Though none of the lithologies used in our inversion are truly olivine free, the KG1 pyroxenite has a comparatively low modal abundance of olivine. Even when we use the KG1 model for the pyroxenitic lithology (which is less dense than an olivine-free pyroxenite, Shorttle et al., 2014 ), our results demonstrate that a $\phi_{\mathrm{px}}=100 \%$ mantle is not simultaneously buoyant and compatible with our $T_{\text {crys }}$ observations. Better constraints could be placed on $\phi_{\mathrm{px}}$ and $\phi_{\mathrm{hz}}$ with a more sophisticated model for forward modelling magma-flux, and the relative contributions of lherzolite- and pyroxenite-derived melts to it ( $X_{\mathrm{px}}$ at ocean islands is likely to be particularly sensitive to the vertical gradient in mantle velocity field).

The posterior distributions from the inversions using both estimates of $T_{\text {crys }}^{\text {primary }}$ demonstrate a negative trade-off between $T_{p}$ and $\phi_{\mathrm{hz}}$. The higher the mantle $\phi_{\mathrm{hz}}$, the greater the thermal buffering effect and, therefore, the smaller the temperature drop during melting. In the inversion where we match the diffusion-corrected $T_{\text {crys }}^{\text {primary }}$, a positive trade-off is ob- 


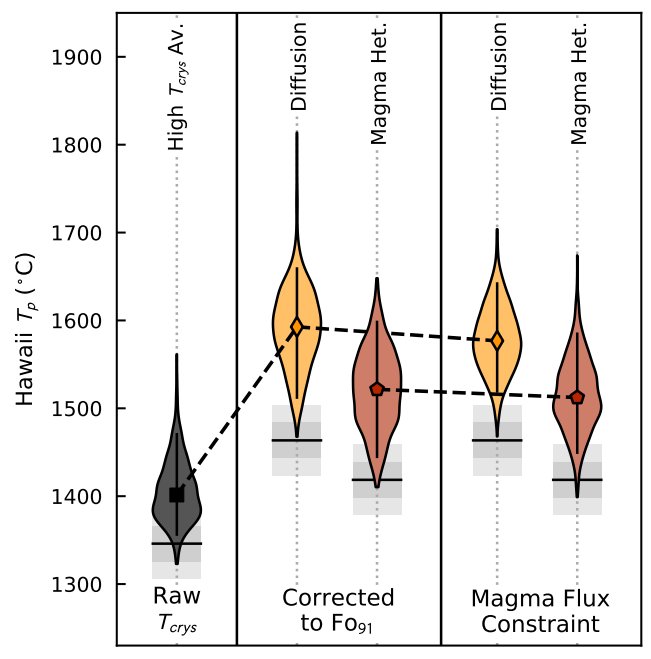

Figure 10. Effect on the posterior Hawaii mantle $T_{p}$ distribution of the various treatments of the raw observations discussed in the text. The left-most distribution is calculated by treating the raw crystallization temperatures $\left(T_{\text {crys }}\right)$ as primary crystallization temperatures (Figure $\left.5 \mathrm{a}\right)$. The middle distributions are calculated from the inferred $T_{\text {crys }}$ for $\mathrm{Fo}_{91}$ olivine crystals, assuming that either the scatter in the raw $T_{\text {crys }}$ population represents diffusion, as shown in Figure $5 \mathrm{~b}$, or arises from magma heterogeneity, demonstrated in Figure 5c. The right-most distributions are generated from the same $T_{\text {crys }}$ inferred for Fo91 crystals, but the inversions were also required to match the magma flux constraint The horizontal bars show the values of $T_{\text {crys }}$ used in each inversion, with their one and two s.d. uncertainties indicated by shading. 
served with $\phi_{\mathrm{px}}$. Increasing mantle $\phi_{\mathrm{px}}$ causes both the mantle density and the temperature drop during melting to increase; both effects are offset by a higher mantle $T_{p}$.

Figure 9 shows the circumstances in which the Hawaiian $T_{\text {crys }}^{\text {primary }}$ and $Q_{m}$ values are consistent with Hawaii having the same mantle $T_{p}$ as Iceland. For the higher $T_{p}$ solution, the most harzburgitic solutions for Hawaii have a similar $T_{p}$ to the solutions for Iceland (black outline on Figure 9e). In this case, a single mantle $T_{p}$ may satisfy both the Iceland and Hawaii constraints, if there is significant $\phi_{\mathrm{hz}}$ variability in the mantle. For the lower $T_{p}$ solution, derived from the magma-heterogeneity correction, the highest $T_{p}$ solutions for Iceland overlap with the posterior Hawaii distributions in both $T_{p}$ and $\phi_{\mathrm{px}}-\phi_{\mathrm{hz}}$ space (Figure $9 \mathrm{~h}$ and i). If the magma-heterogeneity correction is the most appropriate method for estimating $T_{\text {crys }}^{\text {primary }}$, the same mantle $T_{p}, \phi_{\mathrm{px}}$, and $\phi_{\mathrm{hz}}$ can account for both Hawaii and Iceland, despite their differing $T_{\text {crys }}$ values.

Recent plume bouyancy flux estimates (Hoggard et al., 2020; Ribe et al., 2020) suggest the strength of plume upwelling beneath Hawaii is either less strong, or similarly strong to plume upwelling beneath Iceland. Neglecting variation in plume conduit radius, this might be taken to suggest solutions for Hawaii with lower plume buoyancy, i.e. lower $T_{p}$, higher $\phi_{\mathrm{px}}$, and lower $\phi_{\mathrm{hz}}$, are the most likely. This might, in turn, be taken to suggest the magmaheterogeneity correction is the most appropriate method for estimating $T_{\text {crys }}^{\text {primary }}$, as using this $T_{\text {crys }}$ in the inversion results in a greater number of viable solutions that have lower buoyancy than the solutions for Iceland.

\subsubsection{Comparison to previous $T_{p}$ estimates}

Our highest mantle $T_{p}$ estimate for Hawaii $\left(1582_{-65}^{+68 \circ} \mathrm{C}\right)$ is within uncertainty of the $T_{p}$ value $\left(1630 \pm 77^{\circ} \mathrm{C}\right)$ estimated by Putirka et al. (2018), also derived from an estimate of $T_{\text {crys }}^{\text {primary }}$. However, our estimate for $T_{\text {crys }}^{\text {primary }}$ itself $\left(1464 \pm 20^{\circ} \mathrm{C}\right)$ is much lower than the $1549^{\circ} \mathrm{C}$ estimated by Putirka et al. (2018); this discrepancy likely arises from, either, our correction routine underestimating $T_{\text {crys }}^{\text {primary }}$, or the olivine and melt compositions used by Putirka et al. (2018) never having been in equilibrium, as suggested elsewhere (Herzberg, 2011; Matthews et al., 2016; Hole \& Natland, 2019). The larger latent heat of melting correction from which our median $T_{p}$ is calculated reflects the slightly higher median total melt fraction than estimated by Putirka et al. (2018), though the estimates are within uncertainty.

The $T_{p}$ of $1526^{\circ} \mathrm{C}$ estimated for Hawaii by Herzberg and Asimow (2015) using the PRIMELT3 algorithm is intermediate (and within error of) both of our $T_{p}$ estimates, but is closer to our lower estimate, derived using the magma heterogeneity correction routine. Since Herzberg and Asimow (2015) implicitly assume that lithological heterogeneity has a negligible effect on the melting region geotherm, the coincidence of our $T_{p}$ estimates indicates the effects of harzburgite and pyroxenite approximately cancel each other out for our mid-range $T_{p}$ solutions.

Using REE-inversions White and $\mathrm{M}^{\mathrm{c}}$ Kenzie (1995) estimated a $T_{p}$ for Hawaii of $\sim 1450^{\circ} \mathrm{C}$, lower than their $T_{p}$ estimate for Iceland, and only consistent (within uncertainty) with the lower of our two $T_{p}$ estimates. Compared to our model, we might expect REE-inversions to systematically over-estimate $T_{p}$, as any harzburgite present will elevate melt fractions at any given depth, the primary discriminator for $T_{p}$ the White and $\mathrm{M}^{\mathrm{c}}$ Kenzie (1995) model is sensitive to (Appendix A). However, the opposite effect is seen, and might reflect the mantle REE-concentrations being too low in their inversion.

\subsection{The North Atlantic Igneous Province}

In our inversions, all of the North Atlantic Igneous Province (NAIP) locations have estimated $T_{p}$ values within uncertainty of our estimate for modern Iceland. The median $T_{p}$ estimates for Rum and Skye fall only slightly higher than the median Iceland $T_{p}$, despite 
their $T_{\text {crys }}$ estimates being far in excess of those for Iceland (Spice et al., 2016). The higher $T_{\text {crys }}$ values, in absence of a significant difference in $T_{p}$, are mostly accounted for by the smaller latent heat of melting correction resulting from the presence of thick lithosphere beneath Rum and Skye. In contrast, the modest elevation in $T_{\text {crys }}$ for Mull, Baffin, SE Greenland and W Greenland, is not sufficiently offset by the presence of thick lithosphere, meaning that the median $T_{p}$ estimates for the mantle sampled by these eruptions falls lower than the mantle $T_{p}$ estimate for modern Iceland. Here we discuss how our new $T_{p}$ estimates relate to previously published estimates, for a more thorough discussion of how previous $T_{p}$ estimates within the NAIP compare with each other, see Hole and Natland (2019).

Using a combination of geochemistry, geophysics and $T_{\text {crys }}$ observations, Spice et al. (2016) inferred temporal variation in the $T_{p}$ of the Iceland plume; the hottest temperatures at the time of impact and the coolest temperatures in the Tertiary. Whilst the tertiary Iceland olivines have lower $T_{\text {crys }}$ than the recent Iceland and NAIP olivines, they are less forsteritic, implying a greater degree of magmatic evolution. We apply our correction methods to this dataset and estimate a $T_{\text {crys }}^{\text {primary }}$ of $1423^{\circ} \mathrm{C}$ using the diffusive correction, and $1347^{\circ} \mathrm{C}$ using the magma heterogeneity correction (Supporting Figure S.3). Once the correction has been applied, the Tertiary Iceland $T_{\text {crys }}^{\text {primary }}$ could be either greater or lower than modern-day Iceland, and comparable to or slightly lower than the NAIP. As the tectonic setting of the Tertiary lava sequence in Iceland is somewhat uncertain, we do not formally invert the $T_{\text {crys }}^{\text {primary }}$ estimates. However, it seems likely that the magnitude of the correction needed to go from $T_{\text {crys }}$ to $T_{p}$ should be intermediate between Iceland and the NAIP lavas, suggesting $T_{p}$ during the Tertiary is likely in the range $1400-1570^{\circ} \mathrm{C}$. Our results, therefore, suggest that $T_{\text {crys }}$ observations from the NAIP, Tertiary Iceland, and modern Iceland, do not provide supporting evidence for the temporal $T_{p}$ change suggested by Spice et al. (2016), based on geochemical and geophysical observations.

Putirka et al. (2018) estimate the mantle $T_{p}$ for Baffin as $1630 \pm 65^{\circ} \mathrm{C}$, higher than, but within mutual uncertainty of, our estimate. Our median estimates of $T_{p}$ differ for two reasons. First, Putirka et al. (2018) estimate a higher melt-olivine ( $\mathrm{Fog}_{22}$ ) equilibration temperature $\left(1512^{\circ} \mathrm{C}\right)$ than the olivine-spinel equilibration temperatures recorded by the most forsteritic olivine crystals (Spice et al., 2016), the average of which $\left(1413 \pm 22^{\circ} \mathrm{C}\right.$ ) we use in our inversion. Second, Putirka et al. (2018) estimate a slightly higher bulk melt fraction $(0.239 \pm 41)$ than our median result $(\sim 0.15$, Supporting Table S.5). Interestingly, our estimated melt fraction for the lherzolite component ( 0.23 , Supporting Table S.5) is very similar to the estimate by Putirka et al. (2018), who assumed a purely lherzolitic source. The discrepancy in our estimates of crystallization temperature might reflect the olivinespinel thermometer missing some crystallization history, hidden perhaps by re-equilibration of olivine Fo contents with more primitive melts. Alternatively, the olivine-melt thermometer may be in error if an incorrect melt composition was chosen (Herzberg, 2011; Matthews et al., 2016; Hole \& Natland, 2019).

REE-inversions performed on a number of NAIP lavas (White \& $M^{c}$ Kenzie, 1995) suggest that the mantle $T_{p}$ was not significantly different from the present-day Iceland $T_{p}$ of $\sim 1500^{\circ} \mathrm{C}$, consistent with our results. Whilst the presence of harzburgite might bias the REE-inversions towards high values of $T_{p}$, the presence of trace-element enriched pyroxenite will tend to bias the inversions towards lower $T_{p}$ values. It is possible that the effects of pyroxenite and harzburgite act to offset each other, bringing our $T_{p}$ estimates into line with those of White and $\mathrm{M}^{\mathrm{c}}$ Kenzie (1995). Though we incorporate pyroxenite and harzburgite into our $T_{p}$ inversions, in our median $T_{p}$ solutions their effects may also cancel out.

Hole and Millett (2016) applied the PRIMELT3 algorithm to a large number of samples from the NAIP, finding evidence for a $T_{p}$ of $\sim 1550^{\circ} \mathrm{C}$ for Baffin Island and Disko Island, and a $T_{p}$ of $1500-1510^{\circ} \mathrm{C}$ for the British portions of the NAIP and present-day Iceland. Whilst we don't see the offset between Baffin and the other NAIP localities, the $T_{p}$ values estimated by Hole and Millett (2016) are within uncertainty of our own. Applying PRIMELT3 to lavas from Baffin and West Greenland, Willhite et al. (2019) find a $T_{p}$ value 
of $1510-1630^{\circ} \mathrm{C}$, overlapping with our $T_{p}$ estimates, but extending to much higher values. This discrepancy could reflect either the presence of harzburgite in the source, leading to PRIMELT3 overestimating $T_{p}$, or to magmas losing heat as they transit the lithosphere, yielding low values of $T_{\text {crys }}$.

\subsection{The Caribbean Large Igneous Province}

More extreme variations in median $T_{p}$ are seen for the Caribbean LIP (Figure 7). Whilst Curaçao and Gorgona exhibit overlapping posterior $T_{p}$ distributions, the posterior distribution for Tortugal is significantly higher and represents the highest $T_{p}$ calculated here. The mantle $T_{p}$ calculated for Gorgona is within uncertainty of our estimate for Iceland, whilst the Curaçao $T_{p}$ is within uncertainty of MORB. This low value of mantle $T_{p}$ for Curaçao might reflect an insufficient correction for crystallization in calculating the Curaçao $T_{\text {crys }}^{\text {primary }}$.

In the inversions we set the same prior for lithospheric thickness $(60 \pm 10 \mathrm{~km})$ on all three locations. The apparent shift in $T_{p}$ may, therefore, instead reflect variable lithospheric thickness in the vicinity of a spreading centre, as suggested by Trela et al. (2017). In addition to variable lithospheric thickness, Trela et al. (2017) argue that the $T_{\text {crys }}$ observations require variable mantle $T_{p}$.

Our mantle $T_{p}$ estimates are considerably lower $\left(\sim 180^{\circ} \mathrm{C}\right.$ for Curaçao and Gorgona) than those Trela et al. (2017) calculated from whole rock major element chemistry using PRIMELT3. Whilst an underestimation of the required correction to the Curaçao $T_{\text {crys }}$ to estimate $T_{\text {crys }}^{\text {primary }}$ might seem an appealing solution to the discrepancy, we apply no such correction to Gorgona, obtaining $T_{\text {crys }}^{\text {primary }}$ directly from extremely forsteritic crystals. As for the discrepancy in NAIP results discussed in the preceding section, the discrepancy here might also arise from significant harzburgite in the mantle source, or heat loss during magma transport.

Trela et al. (2017) estimate the mantle $T_{p}$ for Tortugal as $\sim 1800^{\circ} \mathrm{C}$, very close to our estimate of $1813_{-149}^{+157 \circ} \mathrm{C}$. The $T_{\text {crys }}$ observations are, therefore, consistent with the $T_{p}$ estimate by Trela et al. (2017) when the relationship between mantle $T_{p}$ and $T_{\text {crys }}^{\text {primary }}$ is robustly quantified. However, whilst the median $T_{p}$ estimate for Tortugal is significantly higher than for the other locations, it is within uncertainty of Emeishan, Karoo, Etendeka and Hawaii. Figure 9k and $9 \mathrm{l}$ demonstrate that the very high Tortugal $T_{\text {crys }}^{\text {primary }}$ can be matched with a more moderate mantle $T_{p}$ if $\phi_{\mathrm{hz}}$ is high and $\phi_{\mathrm{px}}$ is low. This possibility contrasts with the interpretations of Trela et al. (2017), who suggested the Tortugal magmas were derived from an extremely hot mantle plume, akin to Archean plumes that gave rise to komatiites (e.g., Nisbet et al., 1993).

Whilst explaining both Archean komatiites and the Tortugal Phanerozoic komatiite with the same mechanism is appealing, it is difficult to reconcile the existence of a uniquely hot mantle plume in the Phanerozoic with the intrinsic dynamical instability of hot mantle material and the rapidity of thermal diffusion (Shorttle, 2017). The trade-off between mantle $T_{p}$ and $\phi_{\mathrm{px}}$ (Figure 9) demonstrates the plume could have been anomalously pyroxenite rich, perhaps making the bulk material anomalously dense and, therefore, requiring significant heating before a convective instability developed. We propose an alternative mechanism, corresponding to the lower $T_{p}$ region of the posterior distribution, whereby the mantle giving rise to the Tortugal komatiite was anomalously harzburgite-rich and contained a small volume-fraction of more fusible material. The harzburgite would then buffer the temperature during melting to produce extremely hot, high melt-fraction, melts of the fusible material, despite having a $T_{p}$ similar to that of other Phanerozoic mantle plumes. 


\subsection{Karoo, Emeishan and Etendeka Large Igneous Provinces}

The mantle $T_{p}$ estimates for the Karoo, Emeishan and Etendeka LIPs are the most uncertain of all the $T_{p}$ estimates presented here. The large uncertainty derives from high crystallization temperatures favouring high $T_{p}$ solutions: higher mantle $T_{p}$ enables higher $\phi_{\mathrm{px}}$ before the mantle loses its buoyancy, thereby enlarging the range of lithology space of viable solutions. All three LIP mantle $T_{p}$ estimates are within uncertainty of the mantle $T_{p}$ for both Iceland and Hawaii (Figure 7).

Our estimate of the $T_{p}$ for the Emeishan LIP $\left(1555_{-97}^{+100 \circ} \mathrm{C}\right)$ corresponds well with the previous $T_{p}$ estimates $\left(1560-1600^{\circ} \mathrm{C}\right)$ made by Ali et al. (2010) and He et al. (2010) using the PRIMELT2 algorithm (Herzberg \& Asimow, 2008). Tao et al. (2015) estimated a $T_{p}$ of $1740-1810^{\circ} \mathrm{C}$ using the same methodology as Putirka (2008a), much higher and outside the uncertainty of our value. The high $T_{p}$ estimate derives from the high value of $T_{\text {crys }}^{\text {primary }}$ (up to $1536^{\circ} \mathrm{C}$ ) estimated by Tao et al. (2015). If there is significant heterogeneity in magma composition during crystallization of the most forsteritic olivines, an incorrect choice of primary magma chemistry for use in the olivine-liquid thermometer might result in an overestimate of $T_{\text {crys }}^{\text {primary }}$ (Herzberg, 2011; Matthews et al., 2016). Putirka et al. (2018) estimate an even higher $T_{\text {crys }}^{\text {primary }}$ for Emeishan, of $1597^{\circ} \mathrm{C}$; however, their lower estimate of the total melt fraction gave a slightly lower $T_{p}$ estimate of $1700 \pm 67^{\circ} \mathrm{C}$ than Tao et al. (2015).

In estimating the $T_{p}$ for the Karoo LIP we use the $T_{\text {crys }}$ observations by Heinonen et al. (2015), who also estimated mantle $T_{p}$ from $T_{\text {crys }}$. To estimate the latent heat of melting correction Heinonen et al. (2015) applied the Putirka et al. (2007) parameterizations for the relationship between lava major element chemistry and melt fraction, and, therefore, the magnitude of the latent heat of melting. They estimated $T_{p}$ in the range $1540-1640^{\circ} \mathrm{C}$, within uncertainty of our own estimate $\left(1601_{-103}^{+193}\right)$. Heinonen et al. (2015) also applied PRIMELT3 (Herzberg \& Asimow, 2015) to the lava major element chemistry, yielding a $T_{p}$ of $1630^{\circ} \mathrm{C}$. Despite not including the role of lithological heterogeneity, these estimates coincide with our own, suggesting that in our median solution the effects of harzburgite and pyroxenite cancel out. A higher $T_{p}$ estimate of $1785 \pm 55^{\circ} \mathrm{C}$ was made by Putirka (2016), though it is still within uncertainty of our estimate. White (1997) used REE-inversions to estimate the $T_{p}$ for Karoo, finding a much lower value of $\sim 1450^{\circ} \mathrm{C}$. Observations of $\sim 1450^{\circ} \mathrm{C}$ crystallization temperatures suggest that the REE-inversions are significantly underestimating $T_{p}$, most likely due to an inappropriate choice of mantle source REE concentrations, or neglection of the effects of plume-driven upwelling (Maclennan et al., 2001).

Our $T_{p}$ estimate for Etendeka $\left(1599_{-79}^{+104 \circ} \mathrm{C}\right)$ agrees well with the $T_{p}$ estimate made by Jennings et al. (2019) $\left(1623_{-20}^{+22 \circ} \mathrm{C}\right)$ using the same $T_{\text {crys }}$ observations and a similar methodology for the latent heat of melting correction. Jennings et al. (2019) produce a much more precise estimate since they do not consider lithological heterogeneity. Once again, the nearcoincidence of our median $T_{p}$ estimate indicates that in our median solution the effects of harzburgite and pyroxenite cancel each other out. Both estimates are also within uncertainty of the Putirka (2016) $T_{p}$ estimate of $1596 \pm 43$, though like the localities previously discussed, this $T_{p}$ estimate is derived from a higher value of $T_{\text {crys }}^{\text {primary }}\left(1515^{\circ} \mathrm{C}\right)$.

\section{Summary}

Petrological techniques for estimating mantle $T_{p}$ allow us to assess $T_{p}$ on the ancient Earth, where we do not always have reliable constraints from seismic tomography, magma productivity estimates and geomorphology. Previous studies employing the olivine-spinel Al-exchange thermometer have inferred high mantle $T_{p}$ during the generation of large igneous provinces on the basis on the higher crystallization temperatures their olivine cargoes record. In this paper we have laid out a methodology for quantitatively assessing the constraints crystallization temperatures place on mantle $T_{p}$, accounting for potential bi- 
ases in the crystallization temperature record introduced by lithological heterogeneity and lithosphere thickness. This is an important step in validating the use of crystallization temperature estimates for inferring variability in mantle $T_{p}$.

In our inverted dataset we have two locations of modern-day mantle-plume volcanism: Hawaii and Iceland. As discussed in Section 7.3, the inverted $T_{p}$ for Hawaii is much more uncertain than for Iceland; we show that our new crystallization temperature estimates and the previously estimated magma flux for Hawaii are consistent with mantle $T_{p}$ both similar and in excess of Iceland, depending on how the raw crystallization temperature observations are treated (Figure 7). The uncertainty on the $T_{p}$ estimates for the Emeishan, Karoo, and Etendeka large igneous provinces also places them just within uncertainty of the Iceland $T_{p}$. All of the NAIP localities have inverted mantle $T_{p}$ well within uncertainty of the present-day Iceland $T_{p}$.

The Tortugal komatiite olivine crystallization temperatures are consistent with a very hot mantle plume, as suggested by Trela et al. (2017), but are also consistent with a plume temperature similar to that of the Emeishan, Karoo, and Etendeka LIPs, in addition to the highest $T_{p}$ solutions for Hawaii. Such anomalously hot magmas may be derived from a mantle composed largely of harzburgite with a small volume fraction of more fusible mantle components (Figure 9k). If we assume that the mantle $T_{p}$ for Tortugal is similar to the $T_{p}$ for Hawaii and LIPs, all of these locations must have mantle $T_{p}$ in excess of Iceland.

In summary, all of the plume localities we consider here, with the exception of Curaçao, require a mantle temperature significantly in excess of ambient mantle to explain their high crystallization temperatures. The uncertainty introduced from variable mantle lithology means it is generally impossible to infer differences in mantle $T_{p}$ between mantle plumes from crystallization temperatures alone. However, it is likely that at least two values of mantle plume $T_{p}$ are required to explain the crystallization temperatures of Phanerozoic plume-derived magmas.

\section{A The effect of harzburgite on melt chemistry}

When significant quantities of harzburgite are present in the melting region it can act as a thermal buffer, providing heat to the lithologies undergoing melting. This extra heat energy is partly consumed by the melting reactions, enhancing melt production, but also allows the mantle to retain higher temperatures at any given pressure relative to a harzburgite-free mantle (Shorttle et al., 2014; Matthews et al., 2016). Consequently, for a given $T_{p}$, a harzburgite-rich mantle will see higher melting temperatures, which will, in turn, affect the major- and trace-element chemistry of its derivative melts.

To demonstrate this effect we used the alphaMELTS software (Smith \& Asimow, 2005) running the pMELTS model (Ghiorso et al., 2002) to predict the major- and trace-element compositions of melts produced during continuous adiabatic decompression melting, with a porosity of $0.5 \%$. To incorporate the effects of lithological heterogeneity, we used our multilithologic melting model (described in the main text) to calculate the pressure-temperature path followed by the mantle with $\phi_{\mathrm{hz}}=0,0.2,0.4,0.6$, and 0.8 , at a $T_{p}$ of $1450^{\circ} \mathrm{C}$. We did not include any pyroxenite component in the models.

We then ran alphaMELTS along this prescribed pressure-temperature path, starting at $3.95 \mathrm{GPa}$, and ending at $1 \mathrm{GPa}$. The initial bulk-composition was set to the depleted mantle of Workman and Hart (2005), in the NCFMASTO system. The partition coefficients for the trace-elements were set to their default values (McKenzie \& O'Nions, 1991, 1995). To obtain aggregate melts, the extracted melt compositions were summed with equal weighting, up to the pressure at the base of the lithosphere (either 10 or $16 \mathrm{kbar}$ ). Due to the discrepancy in solidus position between pMELTS and our parameterization for KLB-1 lherzolite, all the alphaMELTS calculations started just above the solidus, generating a small quantity of very low-fraction melts. 

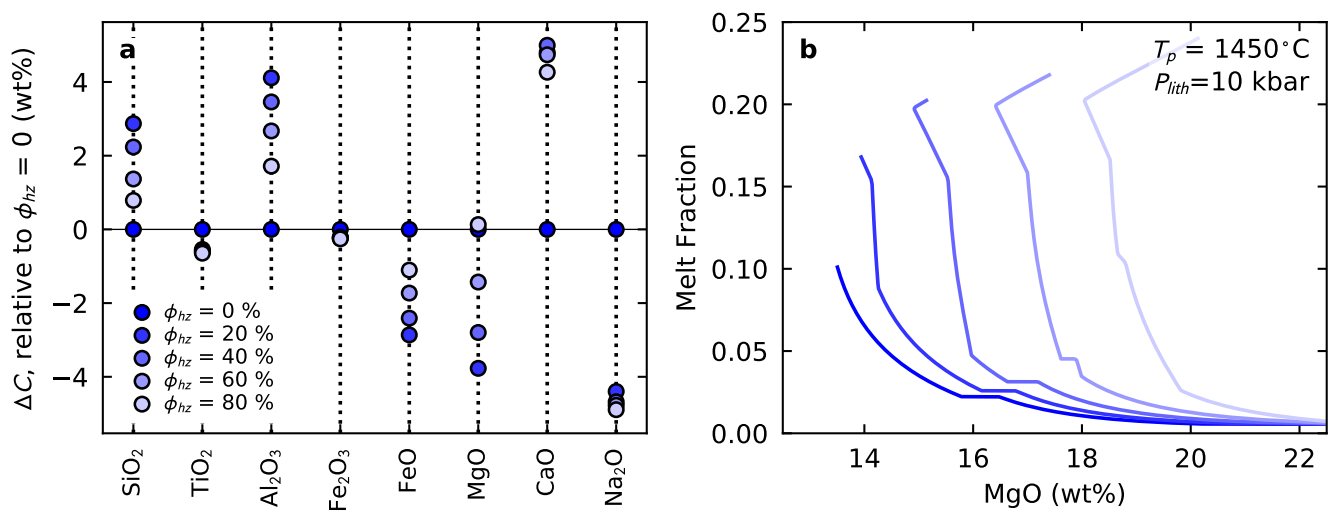

Figure A.1. Results from pMELTS calculations of adiabatic decompression melting of mantle with a $T_{p}$ of $1450^{\circ} \mathrm{C}$, and varying proportions of lherzolite and harzburgite $\left(\phi_{\mathrm{hz}}\right)$. Melting was terminated at $10 \mathrm{kbar}$. See text for more information on how the calculations were performed. Panel a shows the effect of increasing $\phi_{\mathrm{hz}}$ on the major-element composition of aggregate melts. Panel b shows how melt $\mathrm{MgO}$ varies with melt fraction for each of the models, the color and shading of the lines matches the key in panel a. The tail of high $\mathrm{MgO}$ at low melt fraction is an artefact of the calculation method.

Figure A.1 demonstrates that the major-element compositions of lherzolite-derived melts is sensitive to the fraction of harzburgite in the source, causing a change of over $4 \mathrm{wt} \%$ for some oxides in the aggregate melts. Of particular relevance for estimating mantle $T_{p}$ is the control of harzburgite fraction of the $\mathrm{MgO}$ content of melts. For example, the $\mathrm{MgO}$ content of primary melts is a key parameter in the PRIMELT algorithms for determining $T_{p}$ (Herzberg \& Asimow, 2008, 2015). Figure A.1b demonstrates that while MgO stays approximately constant for most of the adiabatic decompression path, the near-constant $\mathrm{MgO}$ value is dependent on $\phi_{\mathrm{hz}}$. High melt $\mathrm{MgO}$ could, therefore, be a product of both high mantle $T_{p}$ and high $\phi_{\mathrm{hz}}$. In particular, the absence of high melt fluxes despite the presence of high $\mathrm{MgO}$ lavas, might be indicative of a largely harzburgitic mantle, rather than extreme values of mantle $T_{p}$.

Since the presence of harzburgite in the melting region can significantly increase the melt fraction of coexisting lherzolite, the phase assemblage equilibrating with the liquid will also be a function of $\phi_{\mathrm{hz}}$. This, in turn, will affect the trace-element chemistry of the derivative melts, demonstrated in Figure A.2. The pressure at the base of the lithosphere was set to $16 \mathrm{kbar}$ in these calculations, such that the $\phi_{\mathrm{hz}}=0$ case has a pronounced "garnetsignature" in its aggregate melts; i.e. a downward trend in normalised concentration is seen in the heavy rare-earth elements at the right-hand side of Figure A.2.

As the fraction of harzburgite in the mantle increases, the garnet signature in the aggregate melts is progressively lost, the concentrations of all trace-elements becomes increasingly diluted, and the signal of extremely incompatible-element depletion (left-hand side of Figure A.2) becomes stronger. These changes in the trace-element systematics are all the result of increased lherzolite melt fraction. This is of relevance for $T_{p}$ estimation as REE-inversions (McKenzie \& O'Nions, 1991) use these systematics to identify mantle $T_{p}$. However, we have demonstrated that harzburgite fraction - independent of mantle $T_{p}$ - can substantially change the trace-element systematics of lavas. This further demonstrates the power of combining geochemical observations with geophysical constraints on magma flux, to simultaneously identify mantle $T_{p}, \phi_{\mathrm{px}}$, and $\phi_{\mathrm{hz}}$. 


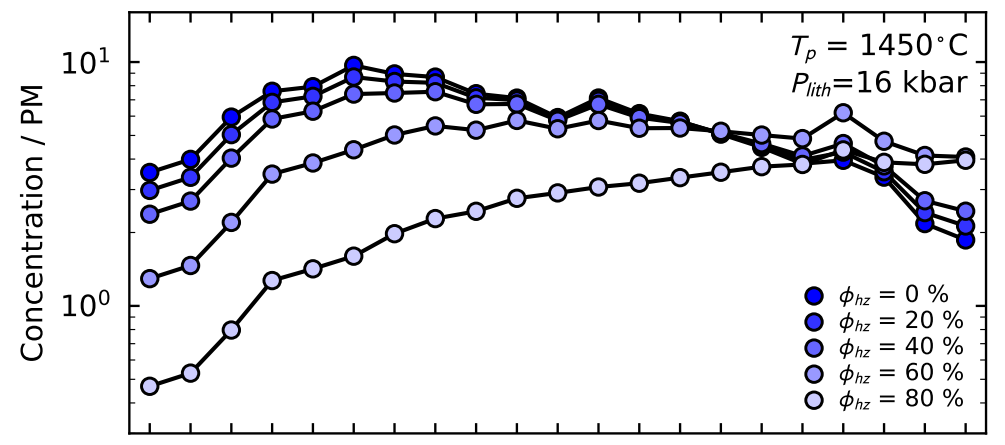

Ba Th U Ta Nb La Sr Pr Nd Zr Hf SmEu Gd Tb Dy Ho Y Er Yb Lu

Figure A.2. The aggregate melt trace-element chemistry calculated by alphaMELTS (implementing pMELTS) for adiabatic decompression melting of mantle with a $T_{p}$ of $1450^{\circ} \mathrm{C}$, and varying proportions of lherzolite and harzburgite $\left(\phi_{\mathrm{hz}}\right)$. The trace element chemistry of the solid lherzolite was set to the Average DMM of Workman and Hart (2005), the harzburgite did not contribute to the melts. Melting was teminated at 16 kbar. See text for more information on how the calculations were performed. Concentrations are normalized to the primitive mantle composition of Palme and O'Neill (2014). 


\section{Acknowledgments}

The authors would like to thank Michael Perfit for provision of the Siqueiros samples and for his comments on a draft of the manuscript. Iris Buisman and Carrie Soderman are thanked for their help with the electron probe analyses. Claude Herzberg, Keith Putirka, Godfrey Fitton, and one anonymous reviewer are thanked for their constructive feedback and efforts to improve the manuscript. The figures in this publication were produced using the Matplotlib python library (Hunter, 2007). This work was supported by a Natural Environment Research Council studentship [NE/L002507/1 and NE/M000427/1] to SM. The analytical data generated by this study is provided in the Supporting Data Sets S.2. and S.4. The python module used to perform the mantle melting calculations (pyMelt) is archived in a Zenodo repository (Matthews et al., 2020). The extension for performing the Bayesian inversion calculations (pyMelt_multinest) is also archived in a Zenodo repository (Matthews \& Shorttle, 2020).

\section{References}

Aghaei, O., Nedimović, M. R., Carton, H., Carbotte, S. M., Canales, J. P., \& Mutter, J. C. (2014). Crustal thickness and moho character of the fast-spreading East Pacific rise from $9^{\circ} 42^{\prime} \mathrm{N}$ to $9^{\circ} 57^{\prime} \mathrm{N}$ from poststack-migrated 3-D MCS data. Geochemistry, Geophysics, Geosystems, 15(3), 634-657.

Ali, J. R., Fitton, J. G., \& Herzberg, C. (2010). Emeishan large igneous province (SW China) and the mantle-plume up-doming hypothesis. Journal of the Geological Society, $167(5), 953-959$.

Alvarado, G. E., Denyer, P., \& Sinton, C. W. (1997). The 89 Ma Tortugal komatiitic suite, Costa Rica: implications for a common geological origin of the Caribbean and Eastern Pacific region from a mantle plume. Geology, 25(5), 439-442.

Bizimis, M., Griselin, M., Lassiter, J. C., Salters, V. J., \& Sen, G. (2007). Ancient recycled mantle lithosphere in the Hawaiian plume: osmium-hafnium isotopic evidence from peridotite mantle xenoliths. Earth and Planetary Science Letters, 257(1), 259-273.

Bock, G. (1991). Long-period S to P converted waves and the onset of partial melting beneath Oahu, Hawaii. Geophysical Research Letters, 18(5), 869-872.

Boudier, F., \& Coleman, R. (1981). Cross section through the peridotite in the Samail ophiolite, southeastern Oman Mountains. Journal of Geophysical Research: Solid Earth, 86(B4), 2573-2592.

Bown, J. W., \& White, R. S. (1994). Variation with spreading rate of oceanic crustal thickness and geochemistry. Earth and Planetary Science Letters, 121 (3-4), 435-449.

Brown, E. L., Petersen, K. D., \& Lesher, C. E. (2020a). Markov chain Monte Carlo inversion of mantle temperature and source composition, with application to Reykjanes Peninsula, Iceland. Earth and Planetary Science Letters, 532, 116007.

Brown, E. L., Petersen, K. D., \& Lesher, C. E. (2020b). Reply to "finding harzburgite in the mantle. a comment on brown et al.(2020):'markov chain monte carlo inversion of mantle temperature and source composition, with application to reykjanes peninsula, iceland"' by shorttle et al.

Buchner, J., Georgakakis, A., Nandra, K., Hsu, L., Rangel, C., Brightman, M., .. Kocevski, D. (2014). X-ray spectral modelling of the AGN obscuring region in the CDFS: Bayesian model selection and catalogue. Astronomy \& Astrophysics, 564, A125.

Byerly, B. L., \& Lassiter, J. C. (2014). Isotopically ultradepleted domains in the convecting upper mantle: Implications for MORB petrogenesis. Geology, 42(3), 203-206.

Campbell, I. H., Griffiths, R., \& Hill, R. (1989). Melting in an Archaean mantle plume: heads it's basalts, tails it's komatiites. Nature, 339(6227), 697.

Campbell, I. H., \& Griffiths, R. W. (1990). Implications of mantle plume structure for the evolution of flood basalts. Earth and Planetary Science Letters, 99(1-2), 79-93.

Cashman, K. V., Sparks, R. S. J., \& Blundy, J. D. (2017). Vertically extensive and unstable magmatic systems: a unified view of igneous processes. Science, 355(6331). 
Cawthorn, R. G. (1975). Degrees of melting in mantle diapirs and the origin of ultrabasic liquids. Earth and Planetary Science Letters, 27(1), 113-120.

Coogan, L., Saunders, A., \& Wilson, R. (2014). Aluminum-in-olivine thermometry of primitive basalts: evidence of an anomalously hot mantle source for large igneous provinces. Chemical Geology, 368, 1-10.

Dannberg, J., \& Sobolev, S. V. (2015). Low-buoyancy thermochemical plumes resolve controversy of classical mantle plume concept. Nature communications, 6(1), 1-9.

Darbyshire, F. A., Priestley, K. F., White, R. S., Stefánsson, R., Gudmundsson, G. B., \& Jakobsdóttir, S. S. (2000). Crustal structure of central and northern Iceland from analysis of teleseismic receiver functions. Geophysical Journal International, 143(1), $163-184$.

Davis, M., White, N., Priestley, K., Baptie, B., \& Tilmann, F. (2012). Crustal structure of the British Isles and its epeirogenic consequences. Geophysical Journal International, $190(2), 705-725$.

Droop, G. (1987). A general equation for estimating $\mathrm{Fe}^{3+}$ concentrations in ferromagnesian silicates and oxides from microprobe analyses, using stoichiometric criteria. Mineralogical magazine, 51(361), 431-435.

D’Errico, M. E., Warren, J., \& Godard, M. (2016). Evidence for chemically heterogeneous Arctic mantle beneath the Gakkel Ridge. Geochimica et Cosmochimica Acta, 174, 291-312.

Eggins, S. (1992). Petrogenesis of Hawaiian tholeiites: 1, phase equilibria constraints. Contributions to Mineralogy and Petrology, 110(2-3), 387-397.

Falloon, T. J., Green, D. H., Danyushevsky, L. V., \& Faul, U. H. (1999). Peridotite melting at 1.0 and $1.5 \mathrm{GPa}$ : an experimental evaluation of techniques using diamond aggregates and mineral mixes for determination of near-solidus melts. Journal of Petrology, 40(9), 1343-1375.

Farnetani, D. G., \& Richards, M. A. (1995). Thermal entrainment and melting in mantle plumes. Earth and Planetary Science Letters, 136(3-4), 251-267.

Feroz, F., \& Hobson, M. (2008). Multimodal nested sampling: an efficient and robust alternative to Markov Chain Monte Carlo methods for astronomical data analyses. Monthly Notices of the Royal Astronomical Society, 384(2), 449-463.

Feroz, F., Hobson, M., \& Bridges, M. (2009). Multinest: an efficient and robust bayesian inference tool for cosmology and particle physics. Monthly Notices of the Royal Astronomical Society, 398(4), 1601-1614.

Feroz, F., Hobson, M., Cameron, E., \& Pettitt, A. (2013). Importance nested sampling and the MultiNest algorithm. arXiv preprint arXiv:1306.2144.

Geissler, W. H., Sodoudi, F., \& Kind, R. (2010). Thickness of the central and eastern European lithosphere as seen by s receiver functions. Geophysical Journal International, $181(2), 604-634$.

Ghiorso, M. S., Hirschmann, M. M., Reiners, P. W., \& Kress III, V. C. (2002). The pMELTS: A revision of MELTS for improved calculation of phase relations and major element partitioning related to partial melting of the mantle to $3 \mathrm{GPa}$. Geochemistry, Geophysics, Geosystems, 3(5), 1-35.

Gill, R., Pedersen, A. K., \& Larsen, J. (1992). Tertiary picrites in West Greenland: melting at the periphery of a plume? Geological Society, London, Special Publications, 68(1), $335-348$.

Gilligan, A., Bastow, I. D., \& Darbyshire, F. A. (2016). Seismological structure of the 1.8 Ga Trans-Hudson Orogen of North America. Geochemistry, Geophysics, Geosystems, $17(6), 2421-2433$.

Godard, M., Jousselin, D., \& Bodinier, J.-L. (2000). Relationships between geochemistry and structure beneath a palaeo-spreading centre: a study of the mantle section in the Oman ophiolite. Earth and Planetary Science Letters, 180(1-2), 133-148.

Griffiths, R. W., \& Campbell, I. H. (1990). Stirring and structure in mantle starting plumes. Earth and Planetary Science Letters, 99(1-2), 66-78. 
Grove, T. L., Kinzler, R. J., \& Bryan, W. B. (1992). Fractionation of mid-ocean ridge basalt (MORB). Mantle flow and melt generation at mid-ocean ridges, 71, 281-310.

Harvey, J., Gannoun, A., Burton, K. W., Rogers, N. W., Alard, O., \& Parkinson, I. J. (2006). Ancient melt extraction from the oceanic upper mantle revealed by Re-Os isotopes in abyssal peridotites from the Mid-Atlantic ridge. Earth and Planetary Science Letters, $244(3), 606-621$.

He, Q., Xiao, L., Balta, B., Gao, R., \& Chen, J. (2010). Variety and complexity of the LatePermian Emeishan basalts: reappraisal of plume-lithosphere interaction processes. Lithos, 119(1-2), 91-107.

Heinonen, J. S., Jennings, E. S., \& Riley, T. R. (2015). Crystallisation temperatures of the most Mg-rich magmas of the Karoo LIP on the basis of Al-in-olivine thermometry. Chemical Geology, 411, 26-35.

Helz, R. T., \& Thornber, C. R. (1987). Geothermometry of Kilauea Iki lava lake, Hawaii. Bulletin of volcanology, 49(5), 651-668.

Herzberg, C. (2004). Partial crystallization of mid-ocean ridge basalts in the crust and mantle. Journal of Petrology, 45(12), 2389-2405.

Herzberg, C. (2011). Basalts as temperature probes of Earth's mantle. Geology, 39(12), $1179-1180$.

Herzberg, C., \& Asimow, P. (2015). PRIMELT3 MEGA.XLSM software for primary magma calculation: Peridotite primary magma $\mathrm{MgO}$ contents from the liquidus to the solidus. Geochemistry, Geophysics, Geosystems, 16(2), 563-578.

Herzberg, C., \& Asimow, P. D. (2008). Petrology of some oceanic island basalts: PRIMELT2. XLS software for primary magma calculation. Geochemistry, Geophysics, Geosystems, 9(9).

Herzberg, C., Gasparik, T., \& Sawamoto, H. (1990). Origin of mantle peridotite: constraints from melting experiments to $16.5 \mathrm{GPa}$. Journal of Geophysical Research: Solid Earth, 95(B10), 15779-15803.

Herzberg, C., \& Gazel, E. (2009). Petrological evidence for secular cooling in mantle plumes. Nature, 458(7238), 619.

Herzberg, C., \& O'Hara, M. (2002). Plume-associated ultramafic magmas of Phanerozoic age. Journal of Petrology, 43(10), 1857-1883.

Herzberg, C., Raterron, P., \& Zhang, J. (2000). New experimental observations on the anhydrous solidus for peridotite KLB-1. Geochemistry, Geophysics, Geosystems, 1(11).

Hirose, K., \& Kushiro, I. (1993). Partial melting of dry peridotites at high pressures: determination of compositions of melts segregated from peridotite using aggregates of diamond. Earth and Planetary Science Letters, 114(4), 477-489.

Hirschmann, M. M. (2000). Mantle solidus: Experimental constraints and the effects of peridotite composition. Geochemistry, Geophysics, Geosystems, 1(10).

Hirschmann, M. M., \& Stolper, E. M. (1996). A possible role for garnet pyroxenite in the origin of the "garnet signature" in MORB. Contributions to Mineralogy and Petrology, $124(2), 185-208$.

Hoggard, M. J., Parnell-Turner, R., \& White, N. (2020). Hotspots and mantle plumes revisited: Towards reconciling the mantle heat transfer discrepancy. Earth and Planetary Science Letters, 542, 116317.

Hole, M. J., \& Millett, J. (2016). Controls of mantle potential temperature and lithospheric thickness on magmatism in the north Atlantic Igneous Province. Journal of Petrology, $57(2), 417-436$.

Hole, M. J., \& Natland, J. H. (2019). Magmatism in the North Atlantic Igneous Province; mantle temperatures, rifting and geodynamics. Earth-Science Reviews.

Holland, T. J., Green, E. C., \& Powell, R. (2018). Melting of peridotites through to granites: a simple thermodynamic model in the system KNCFMASHTOCr. Journal of Petrology.

Holland, T. J., \& Powell, R. (2011). An improved and extended internally consistent thermodynamic dataset for phases of petrological interest, involving a new equation of state for solids. Journal of Metamorphic Geology, 29(3), 333-383. 
Iwamori, H., McKenzie, D., \& Takahashi, E. (1995). Melt generation by isentropic mantle upwelling. Earth and Planetary Science Letters, 134(3-4), 253-266.

Jenkins, J., Cottaar, S., White, R. S., \& Deuss, A. (2016). Depressed mantle discontinuities beneath Iceland: Evidence of a garnet controlled $660 \mathrm{~km}$ discontinuity? Earth and Planetary Science Letters, 433, 159-168.

Jennings, E. S., Gibson, S. A., \& Maclennan, J. (2019). Hot primary melts and mantle source for the Paraná-Etendeka flood basalt province: New constraints from Al-inolivine thermometry. Chemical Geology, 529, 119287.

Jennings, E. S., \& Holland, T. J. (2015). A simple thermodynamic model for melting of peridotite in the system NCFMASOCr. Journal of Petrology, 56(5), 869-892.

Jennings, E. S., Holland, T. J., Shorttle, O., Maclennan, J., \& Gibson, S. A. (2016). The composition of melts from a heterogeneous mantle and the origin of ferropicrite: application of a thermodynamic model. Journal of Petrology, 57(11-12), 2289-2310.

Johnston, A. D. (1986). Anhydrous PT phase relations of near-primary high-alumina basalt from the South Sandwich Islands. Contributions to Mineralogy and Petrology, 92 (3), 368-382.

Katz, R. F., Spiegelman, M., \& Langmuir, C. H. (2003). A new parameterization of hydrous mantle melting. Geochemistry, Geophysics, Geosystems, 4(9).

Kelemen, P. B., Koga, K., \& Shimizu, N. (1997). Geochemistry of gabbro sills in the crust-mantle transition zone of the oman ophiolite: Implications for the origin of the oceanic lower crust. Earth and Planetary Science Letters, 146 (3-4), 475-488.

Kerr, A. C. (2005). La Isla de Gorgona, Colombia: a petrological enigma? Lithos, 84(1-2), $77-101$.

Kinzler, R. J., \& Grove, T. L. (1992). Primary magmas of mid-ocean ridge basalts 1 . experiments and methods. Journal of Geophysical Research: Solid Earth, 97(B5), 6885-6906.

Klein, E. M., \& Langmuir, C. H. (1987). Global correlations of ocean ridge basalt chemistry with axial depth and crustal thickness. Journal of Geophysical Research: Solid Earth, 92(B8), 8089-8115.

Kogiso, T., Hirose, K., \& Takahashi, E. (1998). Melting experiments on homogeneous mixtures of peridotite and basalt: application to the genesis of ocean island basalts. Earth and Planetary Science Letters, 162(1-4), 45-61.

Kogiso, T., Hirschmann, M., \& Pertermann, M. (2004). High-pressure partial melting of mafic lithologies in the mantle. Journal of Petrology, 45(12), 2407-2422.

Kogiso, T., \& Hirschmann, M. M. (2006). Partial melting experiments of bimineralic eclogite and the role of recycled mafic oceanic crust in the genesis of ocean island basalts. Earth and Planetary Science Letters, 249(3-4), 188-199.

Kumar, P., Kind, R., Priestley, K., \& Dahl-Jensen, T. (2007). Crustal structure of Iceland and Greenland from receiver function studies. Journal of Geophysical Research: Solid Earth, 112(B3).

Lambart, S., Baker, M. B., \& Stolper, E. M. (2016). The role of pyroxenite in basalt genesis: Melt-PX, a melting parameterization for mantle pyroxenites between 0.9 and 5 GPa. Journal of Geophysical Research: Solid Earth, 121(8), 5708-5735.

Lambart, S., Laporte, D., \& Schiano, P. (2009). An experimental study of pyroxenite partial melts at 1 and $1.5 \mathrm{GPa}$ : Implications for the major-element composition of mid-ocean ridge basalts. Earth and Planetary Science Letters, 288(1-2), 335-347.

Lambart, S., Laporte, D., \& Schiano, P. (2013). Markers of the pyroxenite contribution in the major-element compositions of oceanic basalts: Review of the experimental constraints. Lithos, 160, 14-36.

Langmuir, C. H., Klein, E. M., \& Plank, T. (1992). Petrological systematics of mid-ocean ridge basalts: constraints on melt generation beneath ocean ridges. GMS, 71, 183280.

Lassiter, J., Byerly, B., Snow, J., \& Hellebrand, E. (2014). Constraints from Os-isotope variations on the origin of Lena Trough abyssal peridotites and implications for the composition and evolution of the depleted upper mantle. Earth and Planetary Science 
Letters, 403, 178-187.

Lee, C.-T. A., Luffi, P., Plank, T., Dalton, H., \& Leeman, W. P. (2009). Constraints on the depths and temperatures of basaltic magma generation on Earth and other terrestrial planets using new thermobarometers for mafic magmas. Earth and Planetary Science Letters, $279(1-2), 20-33$.

Liu, C.-Z., Snow, J. E., Hellebrand, E., Brügmann, G., Von Der Handt, A., Büchl, A., \& Hofmann, A. W. (2008). Ancient, highly heterogeneous mantle beneath Gakkel ridge, Arctic Ocean. Nature, 452(7185), 311.

Maaløe, S. (2004). The PT-phase relations of an MgO-rich Hawaiian tholeiite: the compositions of primary Hawaiian tholeiites. Contributions to Mineralogy and Petrology, $148(2), 236-246$.

Maclennan, J. (2008). Concurrent mixing and cooling of melts under Iceland. Journal of Petrology, 49(11), 1931-1953.

Maclennan, J., M ${ }^{c}$ Kenzie, D., \& Gronvöld, K. (2001). Plume-driven upwelling under central Iceland. Earth and Planetary Science Letters, 194(1), 67-82.

Mallick, S., Standish, J. J., \& Bizimis, M. (2015). Constraints on the mantle mineralogy of an ultra-slow ridge: hafnium isotopes in abyssal peridotites and basalts from the 9-25 E Southwest Indian Ridge. Earth and Planetary Science Letters, 410, 42-53.

Matthews, S., \& Shorttle, O. (2020, July). simonwmatthews/pymelt_multinest v1.0.0. Zenodo. Retrieved from https://doi.org/10.5281/zenodo.3965689 doi: 10.5281/zenodo.3965689

Matthews, S., Shorttle, O., \& Maclennan, J. (2016). The temperature of the Icelandic mantle from olivine-spinel aluminum exchange thermometry. Geochemistry, Geophysics, Geosystems, 17(11), 4725-4752.

Matthews, S., Shorttle, O., \& Wong, K. (2020, September). simonwmatthews/pymelt: First release. Zenodo. Retrieved from https://doi.org/10.5281/zenodo.4011814 doi: 10.5281/zenodo.4011814

Matzen, A. K., Wood, B. J., Baker, M. B., \& Stolper, E. M. (2017). The roles of pyroxenite and peridotite in the mantle sources of oceanic basalts. Nature Geoscience, 10(7), 530 .

$\mathrm{M}^{\mathrm{c}}$ Kenzie, D., \& Bickle, M. (1988). The volume and composition of melt generated by extension of the lithosphere. Journal of petrology, 29(3), 625-679.

McKenzie, D., \& O'Nions, R. (1991). Partial melt distributions from inversion of rare earth element concentrations. Journal of Petrology, 32(5), 1021-1091.

M'enzie, D., \& O'Nions, R. K. (1995). The source regions of ocean island basalts. Journal of petrology, 36(1), 133-159.

Neave, D. A., \& Putirka, K. D. (2017). A new clinopyroxene-liquid barometer, and implications for magma storage pressures under Icelandic rift zones. American Mineralogist, 102(4), 777-794.

Nisbet, E., Cheadle, M., Arndt, N., \& Bickle, M. (1993). Constraining the potential temperature of the Archaean mantle: a review of the evidence from komatiites. Lithos, 30(3-4), 291-307.

Niu, Y., Wilson, M., Humphreys, E. R., \& O'Hara, M. J. (2011). The origin of intra-plate ocean island basalts (OIB): the lid effect and its geodynamic implications. Journal of Petrology, 52(7-8), 1443-1468.

O'Hara, M. (1968). The bearing of phase equilibria studies in synthetic and natural systems on the origin and evolution of basic and ultrabasic rocks. Earth-Science Reviews, 4 , $69-133$.

O'Hara, M. (1965). Primary magmas and the origin of basalts. Scottish Journal of Geology, $1(1), 19-40$.

Palme, H., \& O'Neill, H. (2014). Cosmochemical estimates of mantle composition. planets, asteriods, comets and the solar system, volume 2 of treatise on geochemistry . edited by andrew $m$. davis. Elsevier.

Parnell-Turner, R., White, N., Henstock, T., Murton, B., Maclennan, J., \& Jones, S. M. (2014). A continuous 55-million-year record of transient mantle plume activity beneath 
Iceland. Nature Geoscience, 7(12), 914.

Paulick, H., Bach, W., Godard, M., De Hoog, J., Suhr, G., \& Harvey, J. (2006). Geochemistry of abyssal peridotites (Mid-Atlantic Ridge, 15 20' N, odp leg 209): implications for fluid/rock interaction in slow spreading environments. Chemical geology, 234(3-4), 179-210.

Perfit, M. R., Fornari, D., Ridley, W., Kirk, P., Casey, J., Kastens, K., ... others (1996). Recent volcanism in the Siqueiros transform fault: picritic basalts and implications for MORB magma genesis. Earth and Planetary Science Letters, 141(1-4), 91-108.

Pertermann, M., \& Hirschmann, M. M. (2003). Partial melting experiments on a MORBlike pyroxenite between 2 and $3 \mathrm{GPa}$ : Constraints on the presence of pyroxenite in basalt source regions from solidus location and melting rate. Journal of Geophysical Research: Solid Earth, 108(B2).

Phipps Morgan, J. (2001). Thermodynamics of pressure release melting of a veined plum pudding mantle. Geochemistry, Geophysics, Geosystems, 2(4).

Powell, R., Holland, T. J., \& Worley, B. (1998). Calculating phase diagrams involving solid solutions via non-linear equations, with examples using THERMOCALC. Journal of metamorphic Geology, 16(4), 577-588.

Priestley, K., \& M Menzie, D. (2006). The thermal structure of the lithosphere from shear wave velocities. Earth and Planetary Science Letters, 244(1-2), 285-301.

Putirka, K. D. (1999). Melting depths and mantle heterogeneity beneath Hawaii and the East Pacific Rise: Constraints from $\mathrm{Na} / \mathrm{Ti}$ and rare earth element ratios. Journal of Geophysical Research: Solid Earth, 104(B2), 2817-2829.

Putirka, K. D. (2005). Mantle potential temperatures at Hawaii, Iceland, and the mid-ocean ridge system, as inferred from olivine phenocrysts: Evidence for thermally driven mantle plumes. Geochemistry, Geophysics, Geosystems, 6(5).

Putirka, K. D. (2008a). Excess temperatures at ocean islands: Implications for mantle layering and convection. Geology, 36(4), 283-286.

Putirka, K. D. (2008b). Thermometers and barometers for volcanic systems. Reviews in mineralogy and geochemistry, 69(1), 61-120.

Putirka, K. D. (2016). Rates and styles of planetary cooling on Earth, Moon, Mars, and Vesta, using new models for oxygen fugacity, ferric-ferrous ratios, olivine-liquid Fe- $\mathrm{Mg}$ exchange, and mantle potential temperature. American Mineralogist, 101(4), 819840.

Putirka, K. D., Perfit, M., Ryerson, F., \& Jackson, M. G. (2007). Ambient and excess mantle temperatures, olivine thermometry, and active vs. passive upwelling. Chemical Geology, 241(3-4), 177-206.

Putirka, K. D., Tao, Y., Hari, K., Perfit, M. R., Jackson, M. G., \& Arevalo Jr, R. (2018). The mantle source of thermal plumes: Trace and minor elements in olivine and major oxides of primitive liquids (and why the olivine compositions don't matter). American Mineralogist: Journal of Earth and Planetary Materials, 103(8), 1253-1270.

Reid, I., \& Jackson, H. (1981). Oceanic spreading rate and crustal thickness. Marine Geophysical Researches, 5(2), 165-172.

Ribe, N. M., Tackley, P. J., \& Sanan, P. (2020). The strength of the iceland plume: A geodynamical scaling approach. Earth and Planetary Science Letters, 551, 116570.

Richards, M. A., Duncan, R. A., \& Courtillot, V. E. (1989). Flood basalts and hot-spot tracks: plume heads and tails. Science, 246(4926), 103-107.

Roeder, P., \& Emslie, R. (1970). Olivine-liquid equilibrium. Contributions to mineralogy and petrology, 29(4), 275-289.

Rudge, J. F., Maclennan, J., \& Stracke, A. (2013). The geochemical consequences of mixing melts from a heterogeneous mantle. Geochimica et Cosmochimica Acta, 114, 112-143.

Saal, A., Hart, S., Shimizu, N., Hauri, E., \& Layne, G. (1998). Pb isotopic variability in melt inclusions from oceanic island basalts, Polynesia. Science, 282(5393), 1481-1484.

Salters, V. J., Mallick, S., Hart, S. R., Langmuir, C. E., \& Stracke, A. (2011). Domains of depleted mantle: New evidence from hafnium and neodymium isotopes. Geochemistry, Geophysics, Geosystems, 12(8). 
Salters, V. J., \& Zindler, A. (1995). Extreme ${ }^{176} \mathrm{Hf} /{ }^{177} \mathrm{Hf}$ in the sub-oceanic mantle. Earth and Planetary Science Letters, 129(1-4), 13-30.

Seyler, M., Lorand, J.-P., Toplis, M. J., \& Godard, G. (2004). Asthenospheric metasomatism beneath the mid-ocean ridge: Evidence from depleted abyssal peridotites. Geology, 32(4), 301-304.

Shorttle, O. (2015). Geochemical variability in MORB controlled by concurrent mixing and crystallisation. Earth and Planetary Science Letters, 424, 1-14.

Shorttle, O. (2017). Geodynamics: Hot mantle rising. Nature Geoscience, 10(6), 400-400.

Shorttle, O., \& Maclennan, J. (2011). Compositional trends of Icelandic basalts: Implications for short-length scale lithological heterogeneity in mantle plumes. Geochemistry, Geophysics, Geosystems, 12(11).

Shorttle, O., Maclennan, J., \& Lambart, S. (2014). Quantifying lithological variability in the mantle. Earth and Planetary Science Letters, 395, 24-40.

Shorttle, O., Matthews, S., \& Maclennan, J. (2020). Finding harzburgite in the mantle. a comment on brown et al.(2020):" markov chain monte carlo inversion of mantle temperature and source composition, with application to reykjanes peninsula, iceland" [earth planet. sci. lett. 532 (2020) 116007]. Earth and Planetary Science Letters, 548,116503 .

Shorttle, O., Rudge, J. F., Maclennan, J., \& Rubin, K. H. (2016). A statistical description of concurrent mixing and crystallization during MORB differentiation: implications for trace element enrichment. Journal of Petrology, 57(11-12), 2127-2162.

Sides, I., Edmonds, M., Maclennan, J., Houghton, B. F., Swanson, D., \& Steele-MacInnis, M. J. (2014b). Magma mixing and high fountaining during the 1959 Kilauea iki eruption, hawai'i. Earth and Planetary Science Letters, 400, 102-112.

Sides, I., Edmonds, M., Maclennan, J., Swanson, D., \& Houghton, B. (2014a). Eruption style at Kìlauea volcano in Hawai'i linked to primary melt composition. Nature Geoscience, $7(6), 464$

Smith, P. M., \& Asimow, P. D. (2005). Adiabat_1ph: A new public front-end to the MELTS, pMELTS, and pHMELTS models. Geochemistry, Geophysics, Geosystems, 6(2).

Sobolev, A., \& Shimizu, N. (1994). The origin of typical NMORB: the evidence from a melt inclusion study. Mineral. Mag. A, 58, 862-863.

Sobolev, A. V., Asafov, E. V., Gurenko, A. A., Arndt, N. T., Batanova, V. G., Portnyagin, M. V., ... Krasheninnikov, S. P. (2016). Komatiites reveal a hydrous Archaean deep-mantle reservoir. Nature, $531(7596), 628$.

Sobolev, A. V., Hofmann, A. W., Sobolev, S. V., \& Nikogosian, I. K. (2005). An olivine-free mantle source of Hawaiian shield basalts. Nature, $434(7033), 590$.

Spandler, C., \& O'Neill, H. S. C. (2010). Diffusion and partition coefficients of minor and trace elements in San Carlos olivine at $1,300^{\circ} \mathrm{C}$ with some geochemical implications. Contributions to Mineralogy and Petrology, 159(6), 791-818.

Spice, H. E., Fitton, J. G., \& Kirstein, L. A. (2016). Temperature fluctuation of the Iceland mantle plume through time. Geochemistry, Geophysics, Geosystems, 17(2), 243-254.

Stracke, A., Genske, F., Berndt, J., \& Koornneef, J. M. (2019). Ubiquitous ultra-depleted domains in Earth's mantle. Nature Geoscience, 12(10), 851-855.

Stracke, A., Snow, J. E., Hellebrand, E., Von Der Handt, A., Bourdon, B., Birbaum, K., \& Günther, D. (2011). Abyssal peridotite Hf isotopes identify extreme mantle depletion. Earth and Planetary Science Letters, 308(3), 359-368.

Takahahshi, E., Nakajima, K., \& Wright, T. L. (1998). Origin of the Columbia River basalts: melting model of a heterogeneous plume head. Earth and Planetary Science Letters, 162 (1-4), 63-80.

Takahashi, E. (1986). Melting of a dry peridotite KLB-1 up to 14 GPa: Implications on the origin of peridotitic upper mantle. Journal of Geophysical Research: Solid Earth, 91 (B9), 9367-9382.

Takahashi, E., \& Scarfe, C. M. (1985). Melting of peridotite to $14 \mathrm{GPa}$ and the genesis of komatiite. Nature, 315(6020), 566-568.

Takahashi, E., Shimazaki, T., Tsuzaki, Y., \& Yoshida, H. (1993). Melting study of a 
peridotite KLB-1 to $6.5 \mathrm{GPa}$, and the origin of basaltic magmas. Philosophical Transactions of the Royal Society of London. Series A: Physical and Engineering Sciences, 342(1663), 105-120.

Tao, Y., Putirka, K. D., Hu, R.-Z., \& Li, C. (2015). The magma plumbing system of the Emeishan large igneous province and its role in basaltic magma differentiation in a continental setting. American Mineralogist, 100(11-12), 2509-2517.

Thompson, R., \& Gibson, S. (2000). Transient high temperatures in mantle plume heads inferred from magnesian olivines in Phanerozoic picrites. Nature, 407(6803), 502.

Thompson, R., Gibson, S., Dickin, A., \& Smith, P. (2001). Early Cretaceous basalt and picrite dykes of the southern Etendeka region, NW Namibia: windows into the role of the Tristan mantle plume in Paraná-Etendeka magmatism. Journal of Petrology, 42(11), 2049-2081.

Thomson, A., \& Maclennan, J. (2012). The distribution of olivine compositions in Icelandic basalts and picrites. Journal of Petrology, 54 (4), 745-768.

Toplis, M. (2005). The thermodynamics of iron and magnesium partitioning between olivine and liquid: criteria for assessing and predicting equilibrium in natural and experimental systems. Contributions to Mineralogy and Petrology, 149(1), 22-39.

Trela, J., Gazel, E., Sobolev, A. V., Moore, L., Bizimis, M., Jicha, B., \& Batanova, V. G. (2017). The hottest lavas of the Phanerozoic and the survival of deep Archaean reservoirs. Nature Geoscience, $10(6), 451$.

Trela, J., Vidito, C., Gazel, E., Herzberg, C., Class, C., Whalen, W., ... Alvarado, G. E. (2015). Recycled crust in the Galápagos plume source at 70 Ma: Implications for plume evolution. Earth and Planetary Science Letters, 425, 268-277.

Trønnes, R. G., \& Frost, D. J. (2002). Peridotite melting and mineral-melt partitioning of major and minor elements at 22-24.5 GPa. Earth and Planetary Science Letters, $197(1-2), 117-131$.

Tsuruta, K., \& Takahashi, E. (1998). Melting study of an alkali basalt JB-1 up to 12.5 GPa: behavior of potassium in the deep mantle. Physics of the Earth and Planetary Interiors, 107(1-3), 119-130.

Turcotte, D., \& Schubert, G. (2014). Geodynamics. Cambridge University Press.

Wagner, T., \& Grove, T. (1998). Melt/harzburgite reaction in the petrogenesis of tholeiitic magma from Kilauea volcano, Hawaii. Contributions to Mineralogy and Petrology, $131(1), 1-12$.

Walter, M. J. (1998). Melting of garnet peridotite and the origin of komatiite and depleted lithosphere. Journal of Petrology, 39(1), 29-60.

Wan, Z., Coogan, L. A., \& Canil, D. (2008). Experimental calibration of aluminum partitioning between olivine and spinel as a geothermometer. American Mineralogist, 93(7), 1142-1147.

Wang, Z., \& Gaetani, G. A. (2008). Partitioning of Ni between olivine and siliceous eclogite partial melt: experimental constraints on the mantle source of Hawaiian basalts. Contributions to Mineralogy and Petrology, 156(5), 661-678.

Warren, J. (2016). Global variations in abyssal peridotite compositions. Lithos, 248, 193-219.

Warren, J., Shimizu, N., Sakaguchi, C., Dick, H., \& Nakamura, E. (2009). An assessment of upper mantle heterogeneity based on abyssal peridotite isotopic compositions. Journal of Geophysical Research: Solid Earth, 114(B12).

Warren, J., \& Shirey, S. (2012). Lead and osmium isotopic constraints on the oceanic mantle from single abyssal peridotite sulfides. Earth and Planetary Science Letters, 359, 279-293.

Waterton, P., Pearson, D. G., Kjarsgaard, B., Hulbert, L., Locock, A., Parman, S., \& Davis, B. (2017). Age, origin, and thermal evolution of the ultra-fresh 1.9 Ga Winnipegosis Komatiites, Manitoba, Canada. Lithos, 268, 114-130.

Watson, S. (1993). Rare earth element inversions and percolation models for Hawaii. Journal of Petrology, 34(4), 763-783. 
Watson, S., \& McKenzie, D. (1991). Melt generation by plumes: a study of Hawaiian volcanism. Journal of Petrology, 32(3), 501-537.

Watts, A., \& Ten Brink, U. (1989). Crustal structure, flexure, and subsidence history of the Hawaiian islands. Journal of Geophysical Research: Solid Earth, 94(B8), 1047310500.

Wessel, P. (2016). Regional-residual separation of bathymetry and revised estimates of Hawaii plume flux. Geophysical Journal International, 204(2), 932-947.

White, R. S. (1993). Melt production rates in mantle plumes. Philosophical Transactions of the Royal Society of London. Series A: Physical and Engineering Sciences, 342(1663), $137-153$.

White, R. S. (1997). Mantle plume origin for the Karoo and Ventersdorp flood basalts, South Africa. South African Journal of Geology, 100(4), 271-282.

White, R. S., \& M Menzie, D. (1989). Magmatism at rift zones: the generation of volcanic continental margins and flood basalts. Journal of Geophysical Research: Solid Earth, 94(B6), 7685-7729.

White, R. S., \& M Kenzie, D. (1995). Mantle plumes and flood basalts. Journal of Geophysical Research: Solid Earth, 100(B9), 17543-17585.

White, R. S., M'Kenzie, D., \& O'Nions, R. K. (1992). Oceanic crustal thickness from seismic measurements and rare earth element inversions. Journal of Geophysical Research: Solid Earth, 97(B13), 19683-19715.

Wieser, P. E., Edmonds, M., Maclennan, J., Jenner, F. E., \& Kunz, B. E. (2019). Crystal scavenging from mush piles recorded by melt inclusions. Nature Communications, $10(1), 1-11$.

Willhite, L. N., Jackson, M. G., Blichert-Toft, J., Bindeman, I., Kurz, M. D., Halldórsson, S. A., ... Byerly, B. L. (2019). Hot and heterogenous high- ${ }^{3} \mathrm{He} /{ }^{4} \mathrm{He}$ components: New constraints from proto-Iceland plume lavas from Baffin island. Geochemistry, Geophysics, Geosystems.

Wilson, J. T. (1973). Mantle plumes and plate motions. Tectonophysics, 19(2), 149-164.

Workman, R. K., \& Hart, S. R. (2005). Major and trace element composition of the depleted MORB mantle (DMM). Earth and Planetary Science Letters, 231(1), 53-72.

$\mathrm{Xu}, \mathrm{R} .$, \& Liu, Y. (2016). Al-in-olivine thermometry evidence for the mantle plume origin of the Emeishan large igneous province. Lithos, 266, 362-366.

Xu, Y., Chung, S.-L., Jahn, B.-m., \& Wu, G. (2001). Petrologic and geochemical constraints on the petrogenesis of Permian-Triassic Emeishan flood basalts in southwestern China. Lithos, 58(3-4), 145-168.

Yasuda, A., Fujii, T., \& Kurita, K. (1994). Melting phase relations of an anhydrous midocean ridge basalt from 3 to $20 \mathrm{GPa}$ : Implications for the behavior of subducted oceanic crust in the mantle. Journal of Geophysical Research: Solid Earth, 99(B5), 9401-9414.

Zhang, J., \& Herzberg, C. (1994). Melting experiments on anhydrous peridotite KLB-1 from 5.0 to 22.5 GPa. Journal of Geophysical Research: Solid Earth, 99(B9), 17729-17742.

Zhukova, I., O'Neill, H., \& Campbell, I. H. (2017). A subsidiary fast-diffusing substitution mechanism of $\mathrm{Al}$ in forsterite investigated using diffusion experiments under controlled thermodynamic conditions. Contributions to Mineralogy and Petrology, 172(7), 53. 